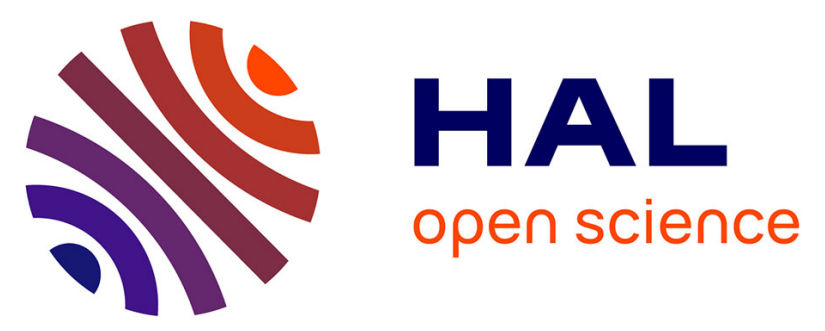

\title{
Coupled hydrogen and phosphorous induced initiation of internal cracks in a large $18 \mathrm{MnNiMo5}$ component
} Jean-Gabriel Sezgin, Cédric Bosch, Aurore Montouchet, Gilles Perrin, Andrej Atrens, Krzysztof Wolski

\section{- To cite this version:}

Jean-Gabriel Sezgin, Cédric Bosch, Aurore Montouchet, Gilles Perrin, Andrej Atrens, et al.. Coupled hydrogen and phosphorous induced initiation of internal cracks in a large $18 \mathrm{MnNiMo5}$ component. Engineering Failure Analysis, 2019, 104, pp.422-438. 10.1016/j.engfailanal.2019.06.014 . emse-02888075

\section{HAL Id: emse-02888075 \\ https://hal-emse.ccsd.cnrs.fr/emse-02888075}

Submitted on 31 Aug 2021

HAL is a multi-disciplinary open access archive for the deposit and dissemination of scientific research documents, whether they are published or not. The documents may come from teaching and research institutions in France or abroad, or from public or private research centers.
L'archive ouverte pluridisciplinaire HAL, est destinée au dépôt et à la diffusion de documents scientifiques de niveau recherche, publiés ou non, émanant des établissements d'enseignement et de recherche français ou étrangers, des laboratoires publics ou privés.

\section{(c)(1)}

Distributed under a Creative Commons Attribution| 4.0 International License 


\section{Coupled hydrogen and phosphorous induced initiation of internal cracks in a large 18MnNiMo5 component}

Jean-Gabriel SEZGIN ${ }^{\mathrm{a},{ }^{*}}$ sezgin.jean-gabriel@aist.go.jp, Cédric BOSCH ${ }^{\mathrm{b}}$, Aurore MONTOUCHET ${ }^{\mathrm{c}}$, Gilles PERRIN ${ }^{\mathrm{d}}$, Andrej ATRENS ${ }^{\mathrm{e}}$, Krzysztof WOLSKI ${ }^{\mathrm{b}}$

${ }^{a}$ AIST-Kyushu University Hydrogen Materials Laboratory (HydroMate), National Institute of Advanced Industrial Science and Technology (AIST), Fukuoka, Japan

${ }^{\mathrm{b}}$ Mines Saint-Etienne, Univ Lyon, CNRS, UMR 5307 LGF, Centre SMS, F - 42023 Saint-Etienne France ${ }^{\mathrm{c}}$ Framatome, Site du Creusot, Le Creusot, FRANCE

${ }^{\mathrm{d}}$ Framatome, Paris, FRANCE

${ }^{\mathrm{e}}$ The University of Queensland, School of Mechanical and Mining Engineering, St Lucia, Qld 4072, Australia

*Corresponding author at: Hydrogen Materials Laboratory (HydroMate), D409-W1 Ito Campus, Kyushu University, 744 Moto-Oka, Nishi-ku, Fukuoka-shi, 819-0395, Japan

\section{ABSTRACT}

This study analyzed a crack in a scrapped $18 \mathrm{MnNiMo5} 80$-tonne shell. The root cause of crack formation was the low fracture toughness caused by a combination of a high hydrogen content and phosphorous segregation, caused by an inappropriate heat treatment. Cracking initiated on $\mathrm{MnS}$ inclusion clusters enabled by hydrogen desorption at the MnS/matrix interfaces. Crack propagation was due to the internal hydrogen pressure causing the crack tip stress intensity factor to exceed the locally-reduced fracture toughness. This new hydrogen induced cracking (HIC) mechanism can be designated as Hydrogen Induced Localised Damage (HILD). Appropriate process controls can eliminate such defects.

Keywords: Hydrogen embrittlement; phosphorous segregation; fracture toughness; blistering; 1620MND5

\subsection{Introduction}

The purpose of this paper is to understand the cracking during production in an 80-tonne, hotformed component, made from $18 \mathrm{MnNiMo5}$ steel (herein designated as 18MND5). This component is typical of a component manufactured by forging a large hollow ingot. A typical example is a reactor pressure vessel, of size of $4 \mathrm{~m}$ in diameter, $4 \mathrm{~m}$ in height, and approximately $200 \mathrm{~mm}$ in thickness. Systematic control is required at each production step. The detection of a significant defect by non-destructive inspection requires interruption of production of the component, and scrapping of the component may be required if the defect is confirmed. 
For the component analyzed herein, the formation of such a defect typically requires contributions from the following three factors: (i) a heterogeneous microstructure, (ii) the presence of $\mathrm{MnS}$ inclusions, and (iii) a sufficient hydrogen concentration.

Firstly, the microstructure of a typical, heavy-forged, low-alloy steel ingot is heterogeneous at several scales: (i) carbon macro-segregation, (ii) ghost lines, and (iii) micro-segregations [1] [2]. The two latter heterogeneities are characterized by increased concentrations of the alloying elements $\mathrm{Mn}, \mathrm{Mo}, \mathrm{Ni}, \mathrm{Si}, \mathrm{S}$ and especially $\mathrm{P}$, such that the local concentration can be twice the nominal composition.

Secondly, such components contain MnS inclusions, although the concentration of $\mathrm{S}$ has been continuously decreased by improved desulfurization techniques, so that the average $\mathrm{S}$ content has been decreased from around $20 \mathrm{ppm}$ in 1980 to $2 \mathrm{ppm}$ in the present practice. The elongated $\mathrm{MnS}$ inclusions are flat and wrought, sometimes as thick as $15 \mu \mathrm{m}$ in a forged component. Their distribution is typically heterogeneous. They form flat ellipsoidal clusters, up to $1 \mathrm{~mm}$ in size, composed of dozens of individual inclusions. They are preferentially located in, or at the vicinity, of ghost lines.

Thirdly, the hydrogen concentration at the end of forging typically exceeds 1 wt.ppm. The typical industrial guidelines imply that the threshold to prevent large components from developing such defects during production is a hydrogen concentration below $1.5 \mathrm{wt}$. ppm. The hydrogen comes from the chemical reaction of the molten steel with the humidity in the atmosphere. The hydrogen is trapped in the ingot by solidification, and a substantial amount remains after the forging step. Hydrogen redistributes during thermo-mechanical processing. This hydrogen redistribution between composition heterogeneities and preexisting cavities has been analyzed using a computational model [3][4]. Simulations have shown that the internal pressure within a cavity, associated with a MnS inclusion, increases during cooling, as the hydrogen solubility decreases. For a set of realistic initial conditions, the maximum pressure may reach $860 \mathrm{MPa}$ at room temperature [4].

These three factors impose the following critical requirements on the thermal history of the component during manufacturing. (i) Hydrogen must be sufficiently degassed by maintaining the component above $200^{\circ} \mathrm{C}$ for a sufficient duration, which depends on the initial hydrogen content. (ii) Internal stress buildup must be prevented by sufficiently slow cooling rates, but the cooling rates must nevertheless be sufficiently fast to prevent phosphorous segregation at prior austenite grain boundaries. (iii) The bainitic microstructure must be optimized by the heat treatment, to achieve the required mechanical properties of strength, ductility and toughness. The details of these processing requirements depend on the composition of the steel. A deviation from these requirements can lead to defect formation, initially as a small cavity that may grow and compromise structure integrity. 
Internal hydrogen can play a critical role, if the hydrogen concentration exceeds the critical value, which is typically below $1 \mathrm{ppm}$. The precise value depends on the manufacturing details. The mechanisms of hydrogen embrittlement are explained in the literature [5] [6] [7] [8] [9] [10]. Hydrogen influences plastic behavior (e.g. by dislocation displacement [11] [12] [13]), can decrease mechanical properties [14] [15] [16], can decrease interatomic cohesive forces [17] [18], can decrease fracture toughness [19], can decrease the threshold stress [21] for crack initiation, and can increase the crack growth rate [20]. Hydrogen cracks in heavy components can occur during the manufacturing process. These cracks can result from the diffusion of internal hydrogen to cavities at $\mathrm{MnS}$ inclusion, where the hydrogen desorbs, pressurizes the cavity sufficiently to cause crack extension when the crack tip stress intensity factor exceeds the locally, hydrogenreduced fracture toughness. The hydrogen concentration is hard to control during manufacturing process, for heavy components exceeding 80 tons [27] [28].

The aims of this paper are (i) to clarify the origin of the internal cracks detected by ultrasonic measurement at the end of the manufacturing process of the $200 \mathrm{~mm}$ thick component made of 18MND5 low-alloy steel, (ii) to propose the scenario of crack initiation and propagation, and (iii) to explain the underlying physical mechanisms.

The origin of the internal crack was clarified by undertaking the following. One typical internal crack was machined from the component and subjected to fractographic analysis at EMSE. A series of ultra-high-vacuum heat treatments reproduced the morphology of the internal surfaces of this industrial crack and explained when the cracking occurred. The relevant mechanical properties of the steel were measured by mechanical tests with simultaneous hydrogen charging. Then, a complete scenario of crack initiation and propagation was proposed, together with an explanation of the underlying physical mechanisms. The potential relevance of these findings is related to other industrial situations.

\subsection{Analysis of the component}

\subsection{Thermo-mechanical history}

Table 1 presents the chemical composition of the 18MND5 low-alloy steel used in the production of this component. The component was scrapped at the end of thermo-mechanical treatment because ultrasonic mapping found penny-shaped cracks, 3 to $20 \mathrm{~mm}$ in diameter, located at the mid thickness of the component, mainly at three fourth height, where carbon segregation was maximal. 
Table 1 - Composition of the 18MND5 low alloy steel, in wt. \%

\begin{tabular}{cccccccccccccc}
\hline & $\mathrm{C}$ & $\mathrm{Mn}$ & $\mathrm{Ni}$ & $\mathrm{Mo}$ & $\mathrm{Cr}$ & $\mathrm{Si}$ & $\mathrm{Cu}$ & $\mathrm{Al}$ & $\mathrm{V}$ & $\mathrm{Sn}$ & $\mathrm{S}$ & $\mathrm{P}$ \\
\hline 18MND5 & 0.181 & 1,458 & 0,724 & 0,501 & 0,254 & 0,173 & 0,052 & 0,015 & 0,005 & 0,004 & 0,0002 & 0,0055 \\
\hline
\end{tabular}

Figure 1 presents the actual thermal cycle of this component. The normal thermal cycle consists of two heat treatments: (i) the outgassing heat treatment and (ii) the precaution heat treatment (austenitisation, quenching and tempering). The outgassing heat treatment is aimed to reduce the average content of internal hydrogen. The outgassing maintains the component at a high temperature, in the ferritic phase, in order to enhance hydrogen diffusivity. No detrimental effects of internal hydrogen are expected after this step. The precaution heat treatment consists of austenitisation, quenching and tempering, and produces the bainitic microstructure to yield the required mechanical properties.

However, the heat treatment was more complex for the component being herein analyzed. Firstly, the standard hydrogen outgassing duration was applied, but it appears that this did not result in a sufficient hydrogen removal. Secondly, after the austenitisation, an unplanned slow cooling occurred in the furnace, instead of the scheduled water quenching. It is expected that this slow cooling produced a ferritic-pearlitic microstructure instead of the required bainitic microstructure produced by the water quenching. After the slow cooling to room temperature, the component was stored for the period of approximately two months. As such a slow cooling was inadequate to produce the required bainitic microstructure, the complete precaution heat treatment was then reapplied to the component. The component was austenitized for the second time, water quenched, tempered and cooled at $30{ }^{\circ} \mathrm{C} / \mathrm{h}$ to room temperature. The component was machined to the required dimensions. Then, however, ultrasonic measurements revealed the presence of pennyshaped cracks, which led to the decision to stop the production, and scrap the component.

Parts of the component containing ultrasonic crack indications were made available for analysis at EMSE. 


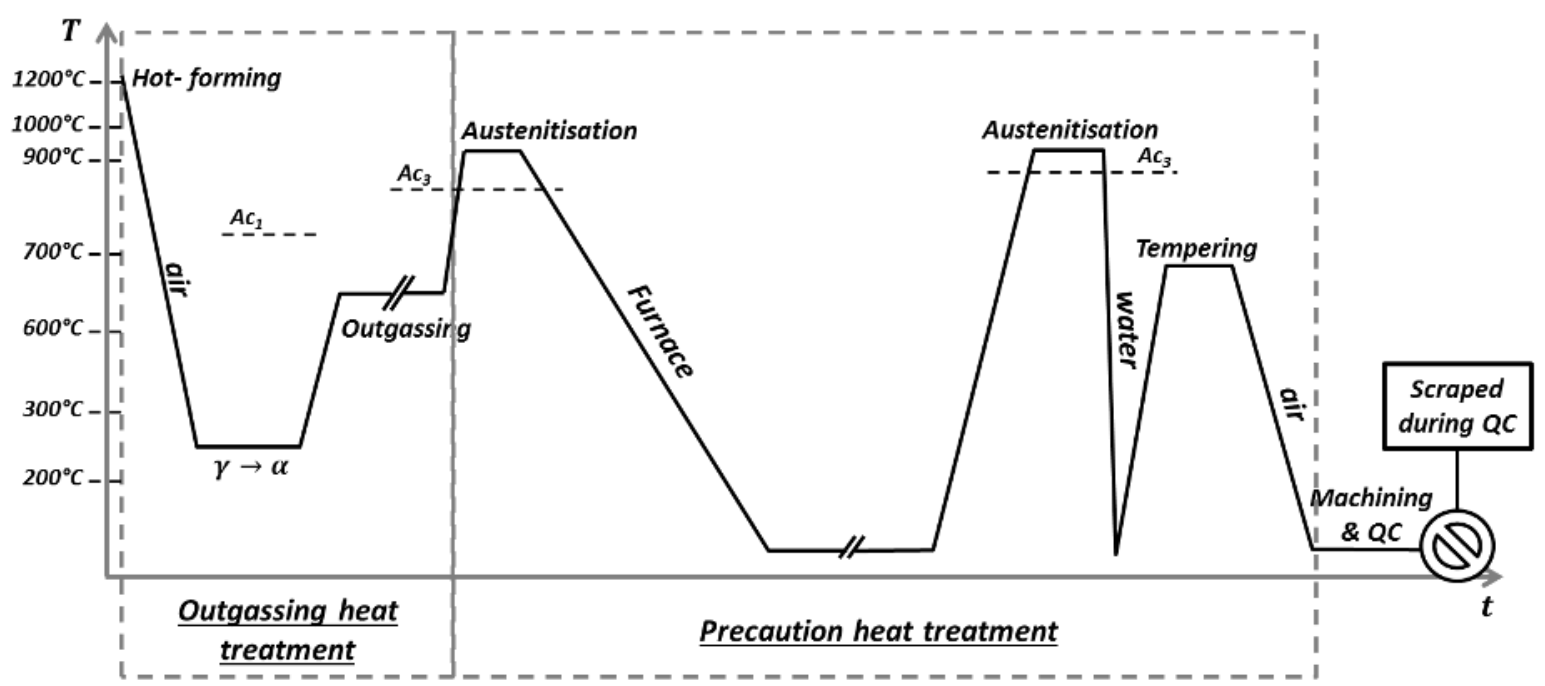

Figure 1 Heat treatment applied to the component. To comply with the microstructure requirements, a second austenitisation was perfor med after the unplanned furnace cooling. Nondestructive examination found pennyshaped cracks and the component was scrapped.

\section{$2.2 \quad$ Analysis of cracks in the component}

Ultrasonic inspection of the material made available to EMSE located a crack within a $30 \mathrm{~mm} \mathrm{x}$ $30 \mathrm{~mm}$ x $40 \mathrm{~mm}$ bloc. A thinner sample was extracted from this bloc and analyzed by tomography (Figure 2-a) and by optical microscopy (Figure 2-b). The overall size of the crack was of the order of $20 \mathrm{~mm}$ in length on the cross section and its opening was 10 to $20 \mu \mathrm{m}$. The position of this crack within the microstructure is presented in Figure 3-a) (SEM image) and Figure 3-b) (EBSD image). The analysis of the crack path with respect to the microstructure usually is extremely helpful [23] [24] in determining the mechanisms of environmentally assisted fracture. However, in this particular case, the second austenitisation must be considered, and for the case the cracks were formed before this austenitisation, the EBSD analysis would be meaningless. 
a)

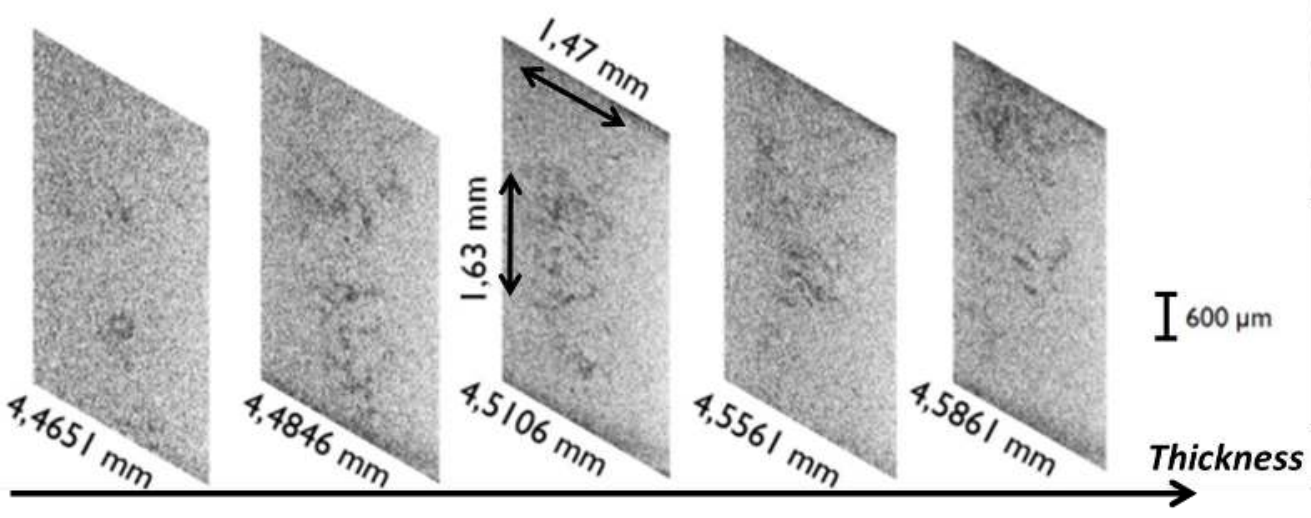

b)

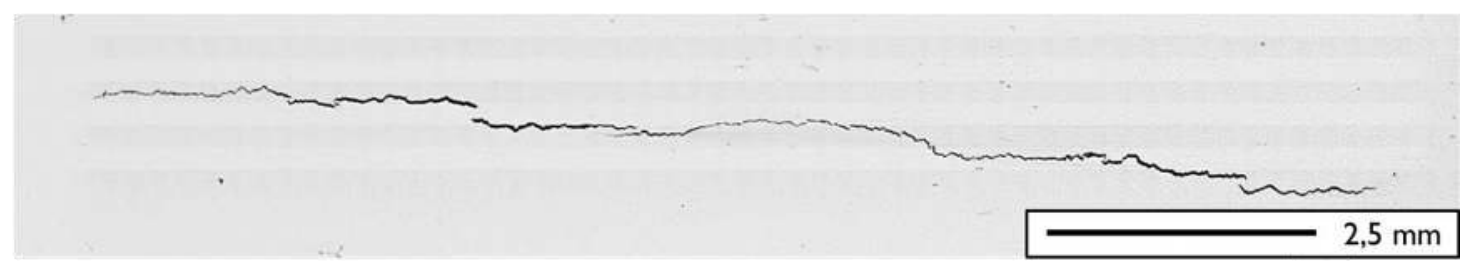

Figure 2 Observation of a crack withdrawn from the scraped component (a) by X-ray micro tomography and (b) by optical microscopy on the cross section

a)

b)
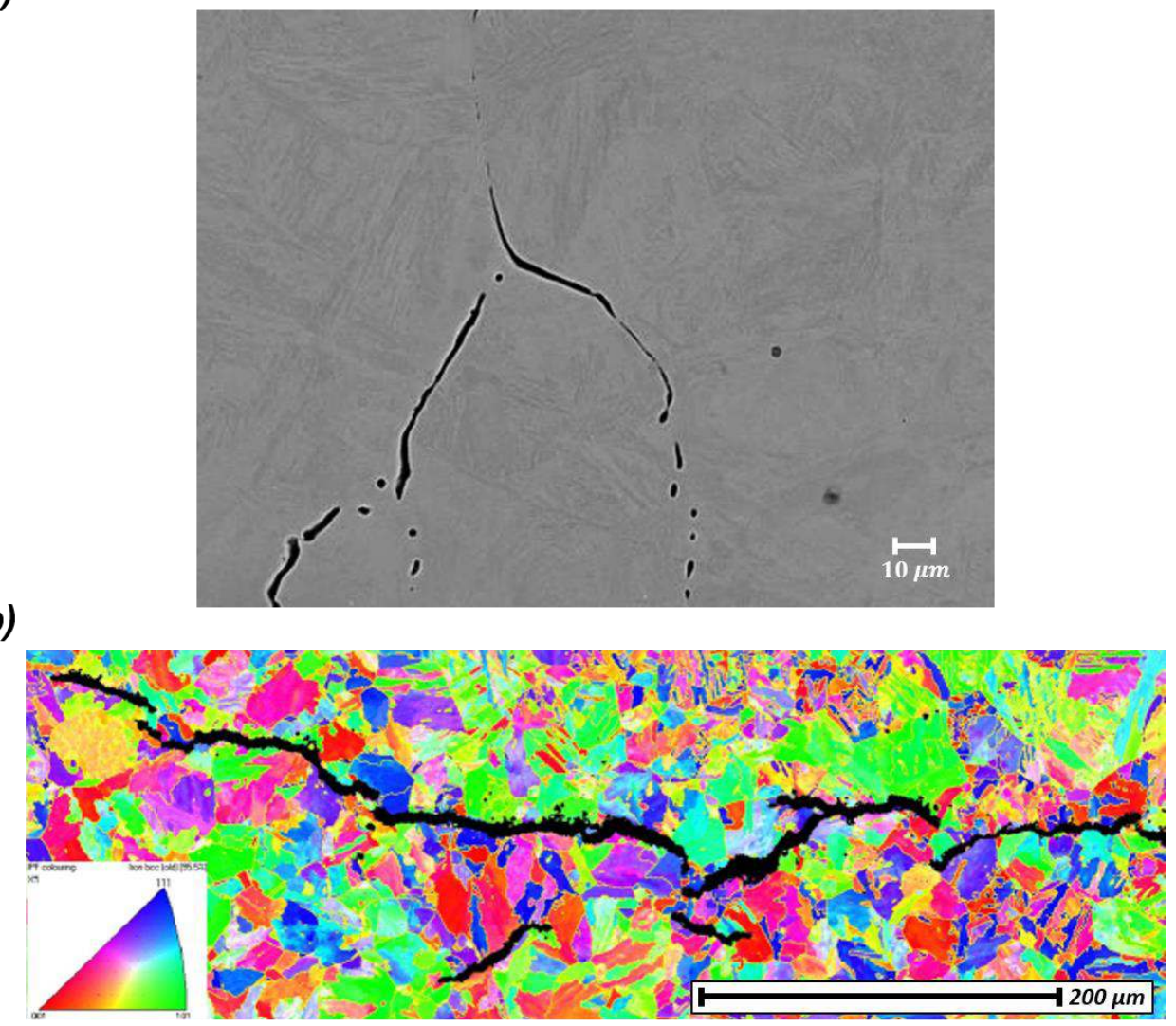

Figure 3 Observation of the crack in relationship to the microstructure (a) through SEM imagery (backscattered electron signal) and (b) EBSD mapping (IPF post processing) 
A second crack was extracted from the initial bloc, and opened after cooling to the temperature of liquid nitrogen, by a purpose-designed bending device, in order to prevent plastic deformation of the surface and to promote brittle facture of the remaining material. Figure 4 and 5 present the scanning electron microscopy (SEM) fractographic analysis of the penny-shaped crack.

Figure 4a reveals that the crack may have started from the area indicated by a dashed ellipse and propagated in the radial direction. Such cracks usually initiate on microstructural defects [25] [26], including inclusions. Figure 4b) provides a magnification of the area within the ellipse of Figure 4a). This micrograph illustrates the smoothed topography of the surface and the presence of small thermal grooves on the surface that ind icate that this crack was exposed to a temperature high enough for massive surface diffusion. Furthermore, the smoothing of the whole internal surface of the crack indicates that no propagation occurred after the last heat treatment. In particular, this observation indicates that this crack could not have formed during the one-month period (dedicated to the machining to final dimensions and necessary to perform ultrasonic measurements, see "machining \& QC" in Figure1) at room temperature prior the final quality control.

a)

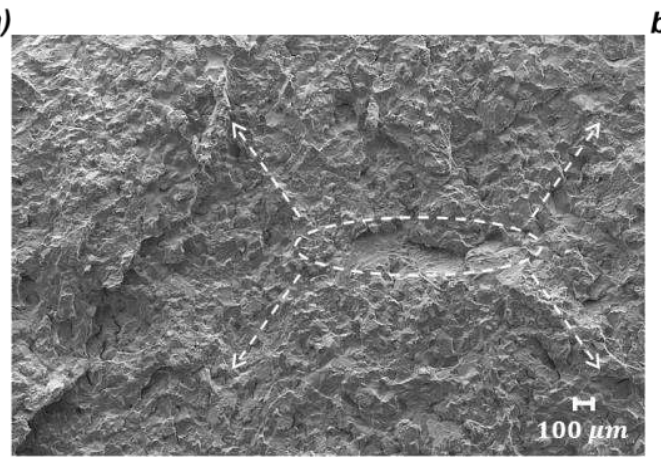

b)

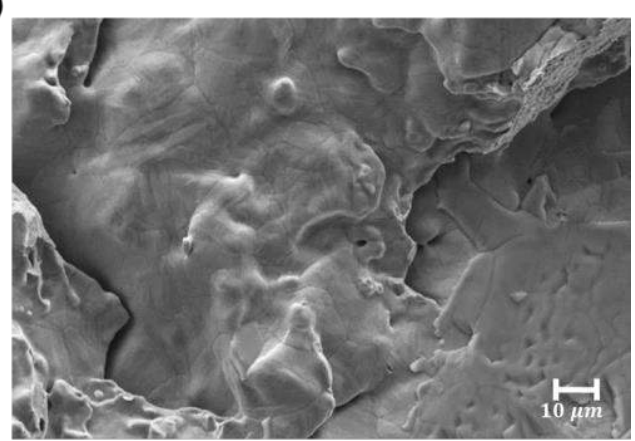

Figure 4 SEM micrograph of the fracture surface of the crack extracted from the component. a) Possible crack initiation site is indicated by the white dashed ellipse. b) The generalized smoothed crack topography indicates that the crack was exposed to high temperatures after crack formation

Figure 5a) presents an area of mainly intergranular fracture. Figure 5b) presents the same area using backscattered electrons. The contrast at the bottom of the micrograph indicates a series of $\mathrm{MnS}$ inclusions forming a large cluster in the immediate vicinity of the intergranular facets. Figure 5c) is a magnification of an area located at the left of Figure 5a). It represents mainly intergranular facets, located on the top of the micrograph, together with some transgranular facets. The smoothing induced by heat treatment may have altered the details of the type of fracture mode and have hidden additional features such as secondary cracks. The mainly intergranular fracture was only present on a limited area of the whole fracture surface, which was mainly transgranular and smoothed, as illustrated in Figure 4a) at low magnification and Figure 4b) at high magnification. 
a)

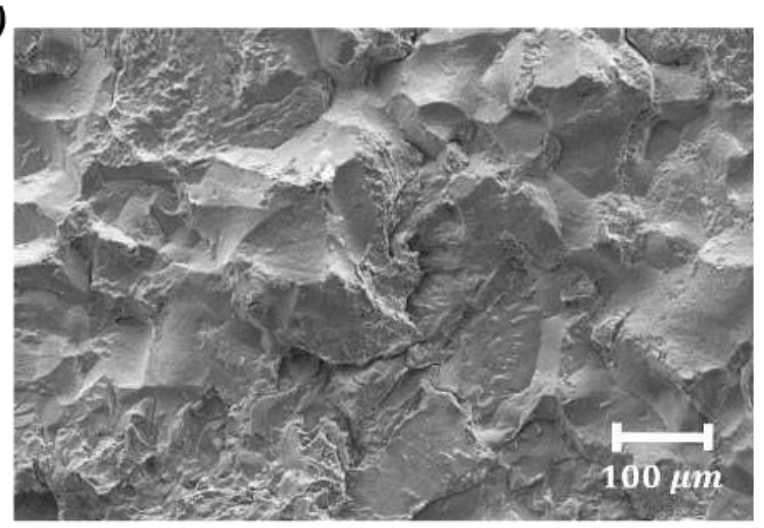

b)

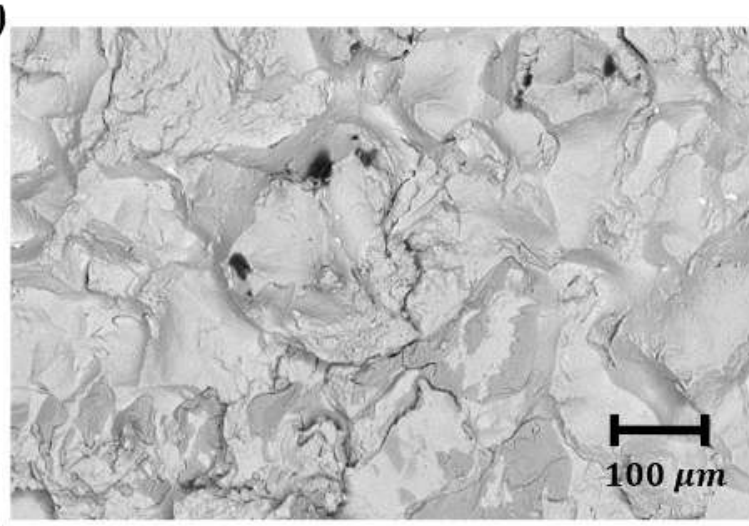

c)

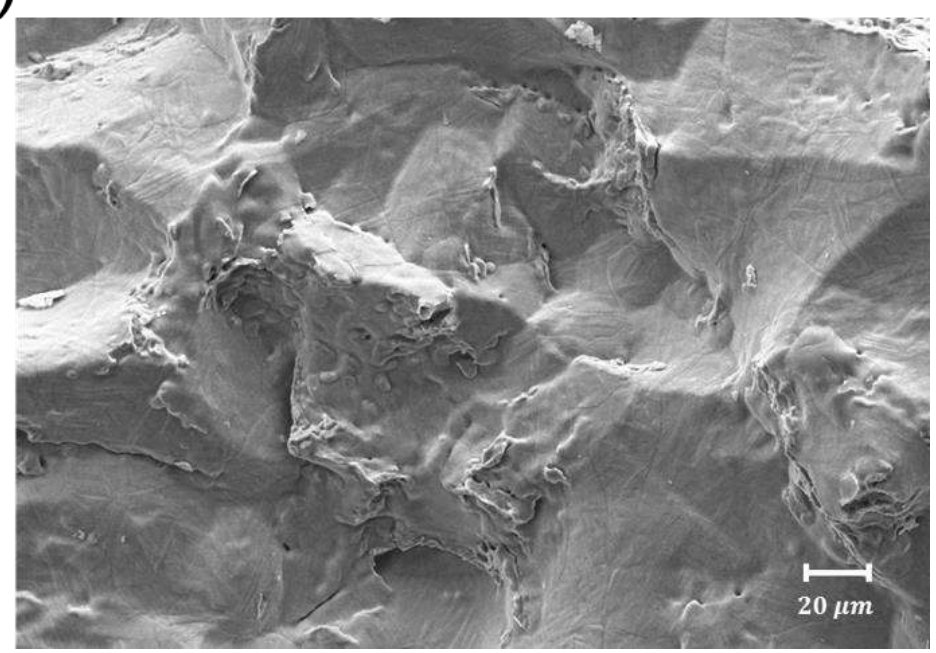

Figure 5 Evidence for large intergranular areas containing MnS inclusions. a) SEM micrograph of a fracture surface of the crack extracted from the component showing a large area of mainly intergranular fracture which was smoothed. b) The same area viewed by backscattered electrons showing several MnS inclusions (grey areas at the bottom) close to the intergranular facets. c) Smoothed intergranular facets.

\subsection{Experimental Methods}

\subsection{UHV heat treatments to reproduce fracture surface smoothing}

Experiments were carried out to determine the temperature and duration of the heat treatment, which would transform a mixed brittle intergranular/transgranular fracture surface into the smoothed crack surface, similar to the one extracted from the component. These experiments required (i) a model brittle surface and (ii) heat treatment conditions to reproduce what happened inside the crack within the component, i.e. totally excluding any oxidation in order to allow surface diffusion. 
The two model brittle surfaces were obtained by fracturing specimens of 16MND5 steel in liquid nitrogen, i.e. well below the brittle to ductile transition temperature. These resulted in mainly transgranular fracture with some intergranular facets corresponding to the areas of microsegregation. The first specimen had a fully transgranular fracture while the second contained both transgranular and intergranular areas.

These two $1 \mathrm{~mm}^{2}$ fracture surfaces were observed by SEM; and then heat treated, and the same areas were again observed in order to quantify the morphological evolution. Heat treatment was done using an ultra-high-vacuum, radiative furnace mounted on an Auger-XPS spectrometer and operated at a vacuum of $10^{-9}$ mbar.

One specimen was subjected to a set of heat treatments aimed at reproducing tempering heat treatments up to the temperature of austenitisation. The specimen was heat treated at $625{ }^{\circ} \mathrm{C}$ for $4 \mathrm{~h}$ followed by SEM observation, heat treated at $725^{\circ} \mathrm{C}$ for $4 \mathrm{~h}$ followed by SEM observation, and heat treated at $825^{\circ} \mathrm{C}$ for $4 \mathrm{~h}$ followed by SEM observation.

Another specimen was heat treated at $950{ }^{\circ} \mathrm{C}$ for 3 hours in order to reproduce the austenitisation heat treatment.

\subsection{Tensile properties and fracture toughness tests}

Slow strain rate tensile tests (SSRT) were carried out to characterize the hydrogen influence on the ultimate tensile strength, UTS, maximal elongation and cross section reduction. Two microstructures were tested using material from the component: (i) the bainitic delivery microstructure and (ii) a ferrite-perlite microstructure that was obtained by austenitisation at $900{ }^{\circ} \mathrm{C}$ followed by a slow cooling at $6.8^{\circ} \mathrm{C} . \mathrm{h}^{-1}$ in order to reproduce the microstructure of the component after the furnace cooling and before the second austenitisation.

The SSRT tests were carried out using axisymmetric smooth tensile specimens with a diameter of $3 \mathrm{~mm}$. They were machined along the radial direction. This direction directly evaluates the influence of planar segregated bands as these are contained in the specimen cross section. The hydrogen charging of the specimens was performed by the application of a cathodic potential on the working electrode using a conventional three-electrode cell with a platinum auxiliary electrode, a saturated calomel electrode (SCE) as a reference electrode, and a $0.3 \mathrm{wt} \% \mathrm{NaCl}$ solution. The hydrogen was produced on the specimen outer surface, and a part of the hydrogen entered the steel by adsorption-absorption. Some tests were performed at the free corrosion potential. To ensure penetration of hydrogen and testing repeatability, metal oxidation was inhibited by deoxygenating of the saline solution by bubbling gaseous pure nitrogen into the deoxygenation tank as shown in Figure 6. 


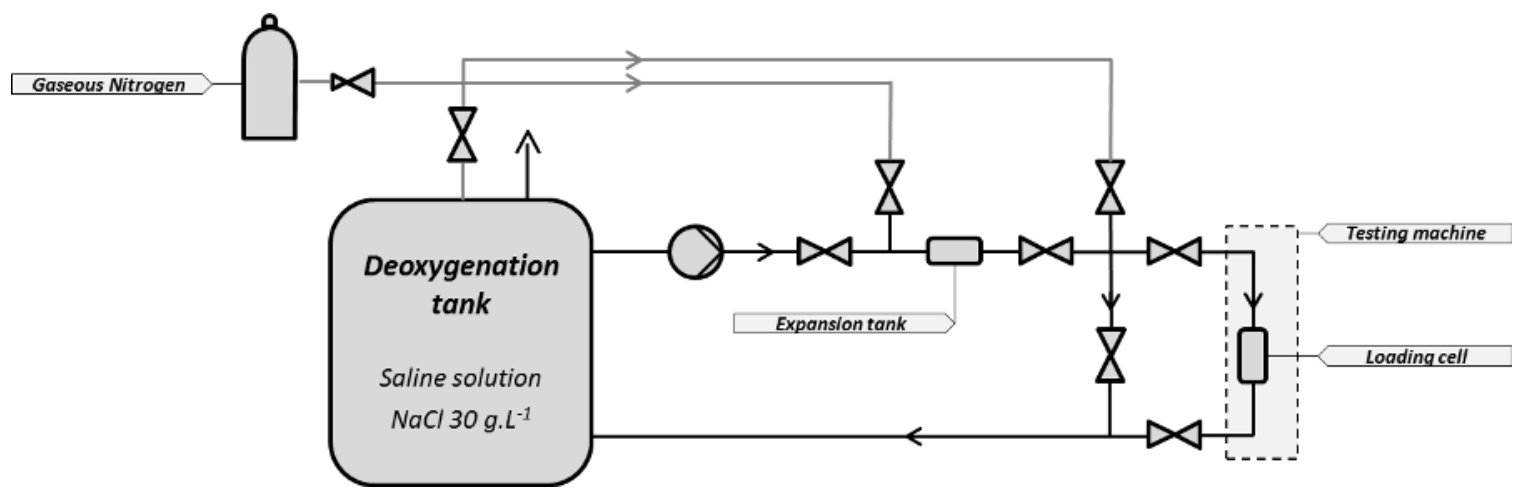

Figure 6 Flow diagram of the de-oxygenation of saline solution for cathodic charging during SSRT.

Slow strain-rate tests (SSRT) at $1.0 \times 10^{-6} \mathrm{~s}^{-1}$ or $5.0 \times 10^{-7} \mathrm{~s}^{-1}$ were performed at room temperature using the following four hydrogen charging conditions:

1. $24 \mathrm{~h}$ precharging at $-1200 \mathrm{mV}_{\mathrm{SCE}}$ followed by a SSRT at this cathodic potential.

2. $24 \mathrm{~h}$ precharging at $-1200 \mathrm{mV}_{\mathrm{SCE}}$ followed by a SSRT at the free corrosion potential, $E_{\text {corr }}$.

3. $8 \mathrm{~h}$ precharging at $-1200 \mathrm{mV}_{\mathrm{SCE}}$ followed by a SSRT at the free corrosion potential, $E_{\text {corr }}$.

4. $4 \mathrm{~h}$ precharging at $-1200 \mathrm{mV}_{\mathrm{SCE}}$ followed by a SSRT at the free corrosion potential, $E_{\text {corr }}$.

The fracture surfaces were analyzed resulting from the test for the condition 1. An estimate of the fracture toughness under hydrogen charging conditions was made.

A fracture toughness test was performed using a precracked compact tension (CT) specimen to measure the threshold stress intensity factor for the hydrogen induced cracking, $K_{\mathrm{IH}}$, corresponding to the bainitic microstructure. This was required because it was expected that the local fracture toughness at $\mathrm{MnS}$ inclusions was decreased by phosphorous segregation. The fracture toughness of the steel is of the order of $200 \mathrm{MPa} \cdot \mathrm{m}^{1 / 2}$ and so requires a CT specimen of dimensions greater than $10 \mathrm{~cm}$. In the presence of hydrogen and phosphorous segregation, however, the fracture toughness is significantly decreased, and consequently requires much smaller specimens.

\subsection{Results}

\subsection{Progressive heat treatment}

The progressive heat treatments from $625{ }^{\circ} \mathrm{C}$ to $825{ }^{\circ} \mathrm{C}$ were performed in three sequential steps, each followed by SEM fractographic observations. Figure 7 shows micrographs of the same area after each heat treatment. Fig. 7a) presents the initial reference condition, and (b,c,d) correspond to observations after $625{ }^{\circ} \mathrm{C}, 725^{\circ} \mathrm{C}$ and $825{ }^{\circ} \mathrm{C}$ heat treatments respectively. This figure shows the evolution of the morphology of the intergranular surface with the progressive smoothing of the grainy-texture typical of this type of fracture. 
a)

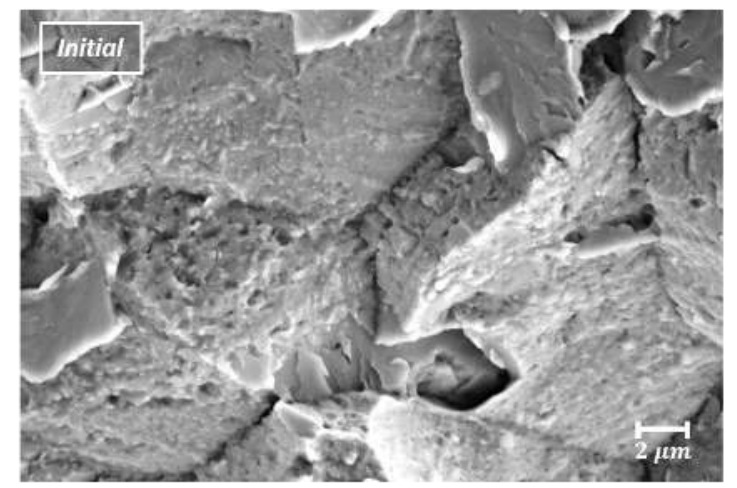

c)

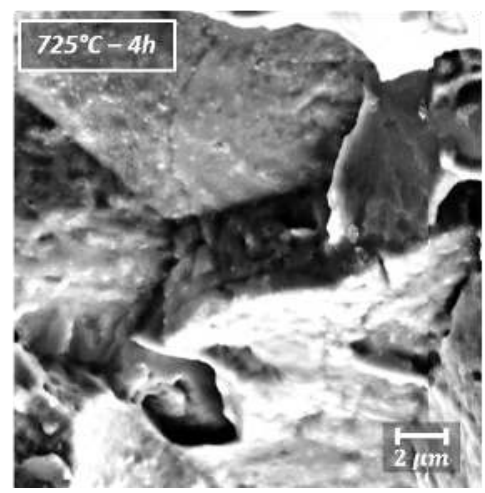

b)

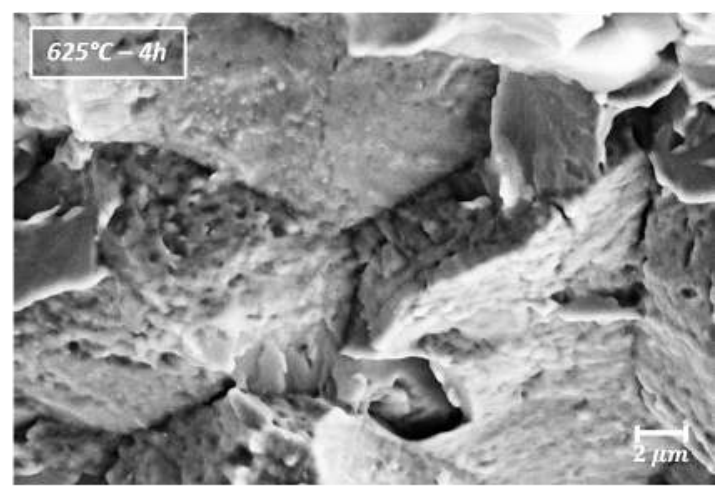

d)

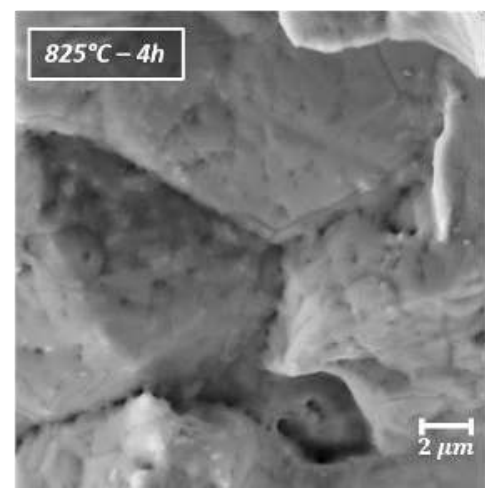

Figure 7 SEM observations of the morphological evolution of intergranular facets following progressive heating under UHV conditions. Four successive steps are represented: (a) initial reference condition, (b) $625^{\circ} \mathrm{C}$ for $4 \mathrm{~h}$, (c) $725^{\circ} \mathrm{C}$ for $4 \mathrm{~h}$, (d), $825^{\circ} \mathrm{C}$ for $4 \mathrm{~h}$.

After the heat treatment at $825^{\circ} \mathrm{C}$ the smoothing is significant but less pronounced than that of the industrial crack from the component presented in Figure 5, especially 5c.

\subsection{Heat treatment at $950{ }^{\circ} \mathrm{C}$}

This heat treatment was aimed to reproduce the effect of the austenitisation heat treatment on the second specimen, which had a transgranular fracture surface. Figure 8 presents the fracture surface before (a) and after (b) this heat treatment at $950{ }^{\circ} \mathrm{C}$ for 3 hours. Figure 8 a shows the pattern of sharp angularities, which are characteristic of this type of brittle fracture. In contrast, after the heat treatment, the surface was smoothed and not angular anymore. Moreover, the comparison of cleavage planes shows that river patterns had vanished following this heat treatment. The tiny thermal grooves might correspond to boundaries between packets of bainite. They can also indicate the emergence of prior austenite grain boundaries due to the heating above the $\mathrm{Ac}_{1}$ temperature. Figure $8 \mathrm{c}$ ) and (d) are magnifications of the initially sharp angle marked with a white circle. A comparison between these two micrographs can be quantitatively expressed by a local radius of curvature after heat treatment. This radius represented by a yellow circle on Figure 8d) was $900 \mathrm{~nm}$, measured by an image processing technique. Figure 9 presents another area of the transgranular fracture surface before (a) and after heat treatment (b). The observed smoothing was similar to that presented in Figure $4 \mathrm{~b}$. 
a)

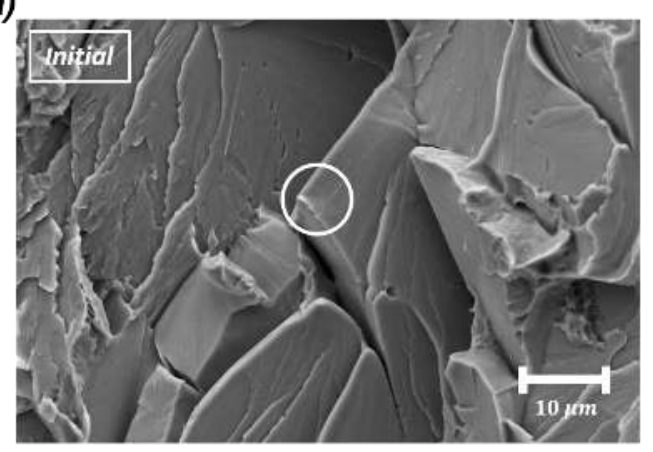

c)

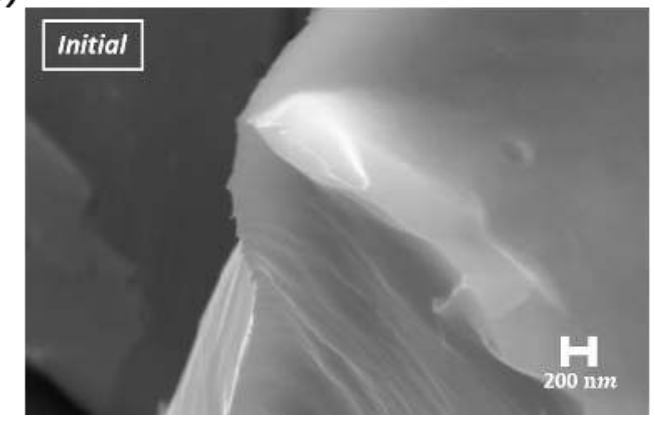

b)

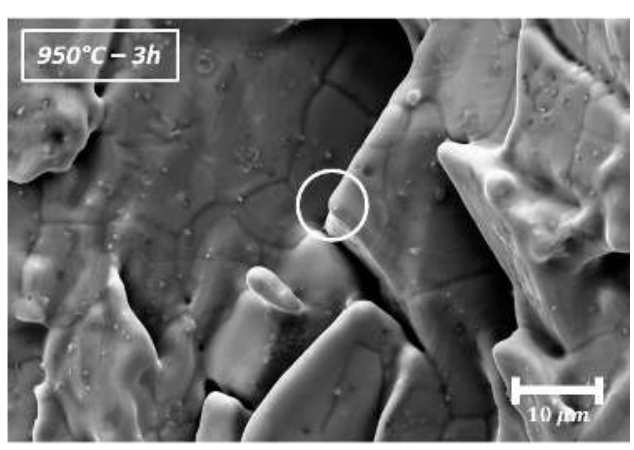

d)

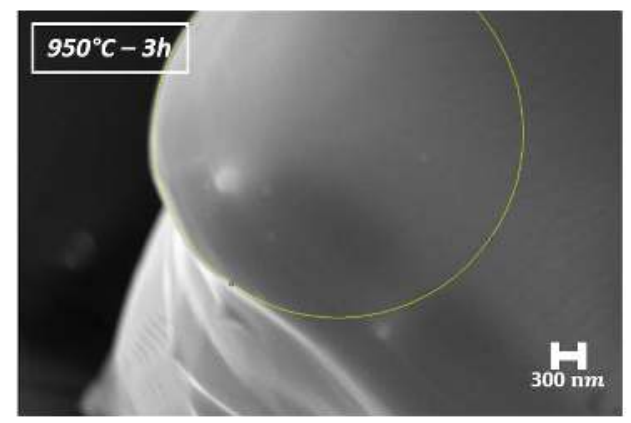

Figure $8 \mathrm{~S} \mathrm{EM}$ micrographs of a transgranul ar facet be fore (a,c) and after (b,d) a $950{ }^{\circ} \mathrm{C}$ heat treatment under UHV conditions for $3 \mathrm{~h}$. a) Transgranular fracture. b) Smoothed facet after exposure to $950{ }^{\circ} \mathrm{C}$. c) Foc us on the sharp angularity indicated in (a) before heat treatment. d) Foc us of the sharp angularity indicated in (b) after heat treatment. The heat treatment has introduced a radius of curvature of $900 \mathrm{~nm}$, which is represented on the micrograph by the yellow circle.
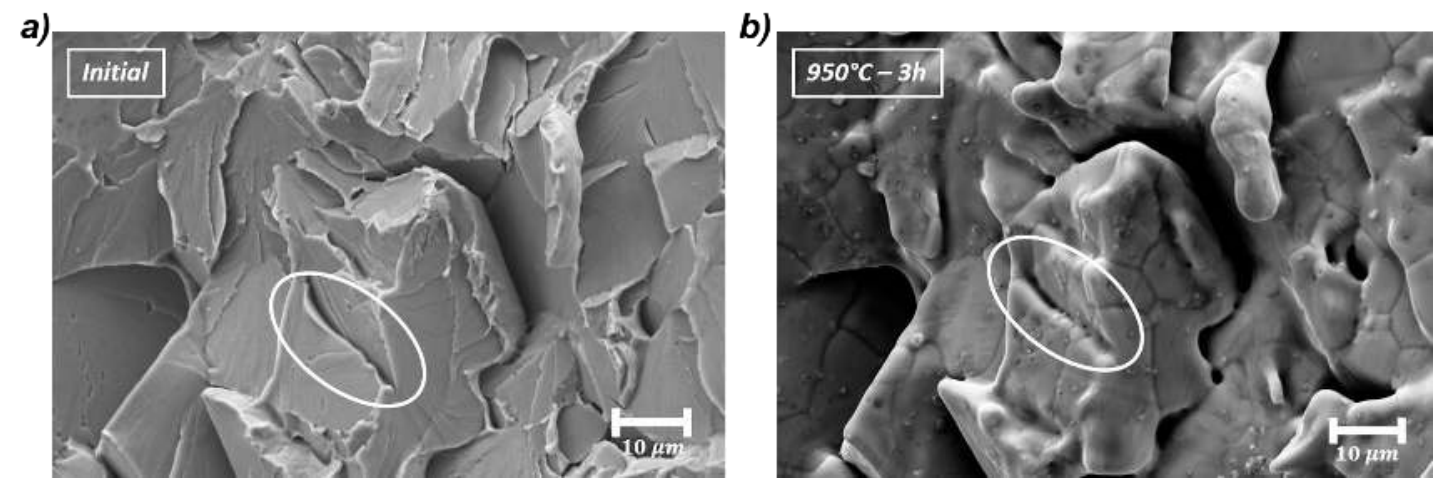

Figure $9 \mathrm{~S} \mathrm{EM} \mathrm{micrographs} \mathrm{of} \mathrm{a} \mathrm{transgranul} \mathrm{ar} \mathrm{facet} \mathrm{before} \mathrm{(a)} \mathrm{and} \mathrm{after} \mathrm{(b)} \mathrm{a} 950{ }^{\circ} \mathrm{C}$ he at treatment in UHV condition for $3 \mathrm{~h}$. a) Sharp crack tip indicated by an ellipse. b) Creation of bridges linking both sides of the crack tip especially in the thinnest areas

The observation of morphological evolution of the fracture surface as a function of temperature for the relatively short durations of 3 to 4 hours indicated a progressive smoothing of both intergranular and transgranular fracture surfaces. The highest temperature produced smoothing similar to that on the crack extracted from the industrial component. At this temperature the smoothing was so pronounced that microscopic features like the granny morphology on the individual intergranular facet or river lines on individual transgranular facet tended to disappear due to surface diffusion. These observations indicate that the initially brittle surface of the 
industrial crack was exposed to the austenitisation temperature, and in particular to the second austenitisation heat treatment. Clearly, the cracks were formed before this austenitisation, during the unplanned slow cooling down to the room temperature or during the subsequent 1,5 months of storage.

\subsection{Hydrogen influence on tensile properties}

The results of the slow tensile tests are presented in Figure 10, Table 2 and Table 3. Figure 10a) presents the stress-strain curves for two reference specimens tested in air at room temperature. Both, exhibited ductile behavior: the specimen with the bainitic microstructure and the specimen with the ferrite-pearlitic microstructure. Figure 10b) presents the effect of hydrogen on the bainitic microstructure. The comparison with the air reference specimen indicates a progressive embrittlement as the severity of the charging condition is increased. Testing conditions 3 and 4 produced only a small effect of hydrogen on the mechanical behavior. Loading with charging conditions 1 and 2 significantly changed the stress-strain curves. There was a significant decrease of strength and reduced plasticity, especially for condition 1. The load decrease was compatible with centripetal crack propagation at the UTS across the round section until specimen failure. Figure 10c) presents the results for the ferrite-perlite microstructure. These stress-strain curves lead to similar conclusions. The intensity of HE increased with the testing severity. The presence of hydrogen mainly decreased plasticity. A comparison of Figure 10b) and Figure 10c) indicates that the hydrogen sensitivity of the bainitic microstructure was significantly higher.
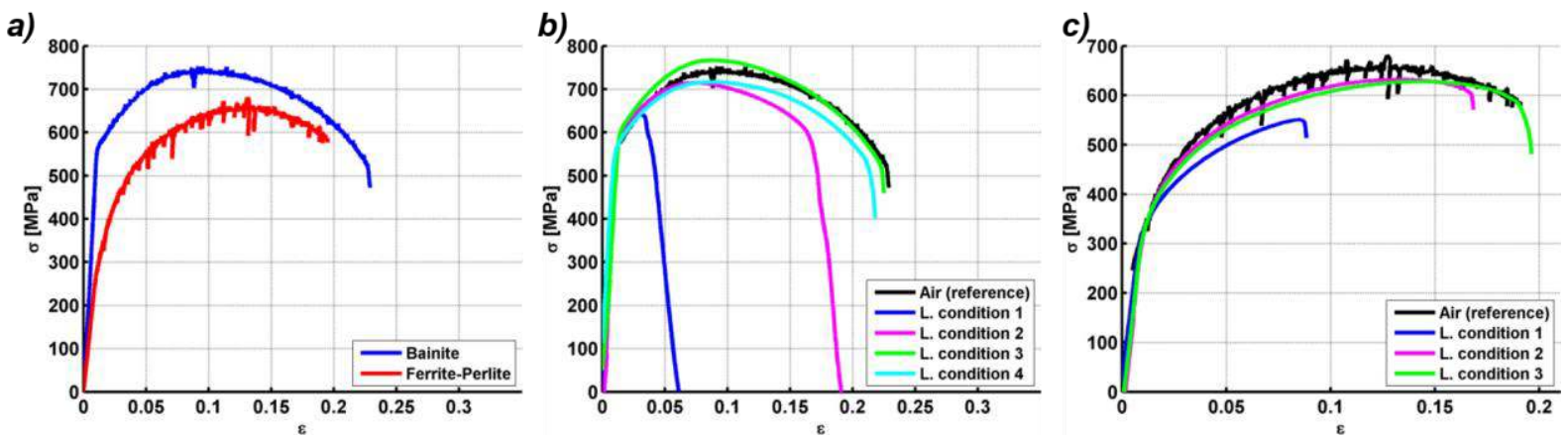

Figure 10 Tensile stress-strain curves for: (a) both bainite and ferrite-perlite microstructures in air at $10^{-6} \mathrm{~s}^{-1}$, (b) bainitic microstructure under different cathodic charging conditions at $5,0.10^{-7} \mathrm{~s}^{-1}$, and (c) ferrite-perlite micros tructure under different cathodic charging conditions at $5,0.10^{-7} \mathrm{~s}^{-1}$

Table 2 Mechanical property values (UTS, elongation to fracture, cross-section reduction) of specimens with a bainitic microstructure for different charging conditions, and measured average content of hydrogen.

\begin{tabular}{ccccccc}
\hline Condition & Precharging & $\boldsymbol{E}_{\text {Test }}$ & UTS & $\boldsymbol{\epsilon}_{\mathbf{A}}$ & $\boldsymbol{\epsilon}_{\mathbf{N}}$ & $\boldsymbol{c}_{\text {avg }}(\boldsymbol{H})$ \\
\hline Reference & -- & -- & $742 \mathrm{MPa}$ & $21,8 \%$ & $69,3 \%$ & $0,72 \mathrm{ppm} \pm 0,07$ \\
$\mathbf{1}$ & $-1200 \mathrm{mV}_{\mathrm{SCE}}, 24 \mathrm{~h}$ & $\begin{array}{c}\text { Cathodic } \\
-1200 \mathrm{mV}_{\mathrm{SCE}}\end{array}$ & $642 \mathrm{MPa}$ & $6,2 \%$ & $12,9 \%$ & $1,32 \mathrm{ppm} \pm 0,32$ \\
$\mathbf{2}$ & $-1200 \mathrm{mV}_{\mathrm{SCE}}, 24 \mathrm{~h}$ & $E_{\text {corr }}$ & $715 \mathrm{MPa}$ & $19,3 \%$ & $39,1 \%$ & $0,91 \mathrm{ppm} \pm 0,08$ \\
\hline
\end{tabular}




\begin{tabular}{|c|c|c|c|c|c|c|}
\hline 3 & $-1200 \mathrm{mV}_{\mathrm{SCE}}, 8 \mathrm{~h}$ & $E_{\text {corr }}$ & $788 \mathrm{MPa}$ & $21,3 \%$ & $65,8 \%$ & $0,84 \mathrm{ppm} \pm 0,11$ \\
\hline A & $-1200 \mathrm{mV} / \mathrm{SCE}, 4 \mathrm{~h}$ & $E_{\text {corr }}$ & $764 \mathrm{MPa}$ & $20,6 \%$ & $67,7 \%$ & $0,72 \mathrm{ppm} \pm 0,07$ \\
\hline
\end{tabular}

Table 3 Mechanical property values (UTS, elongation to fracture, cross-section reduction) of specimens with a ferrite-perlite microstructure for different charging conditions

\begin{tabular}{cccccc}
\hline Condition & Precharging & $\boldsymbol{E}_{\text {Test }}$ & UTS & $\boldsymbol{\epsilon}_{\mathbf{N}}$ & $\boldsymbol{\epsilon}_{\mathbf{Z}}$ \\
\hline Reference & -- & -- & $659 \mathrm{MPa}$ & $17 \%$ & $52,2 \%$ \\
$\mathbf{1}$ & $-1200 \mathrm{mV} / \mathrm{SCE}, 24 \mathrm{~h}$ & $\begin{array}{c}\text { Cathodic } \\
\text {-1200 mV/SCE }\end{array}$ & $551 \mathrm{MPa}$ & $7 \%$ & $18,3 \%$ \\
$\mathbf{2}$ & $-1200 \mathrm{mV} / \mathrm{SCE}, 24 \mathrm{~h}$ & $E_{\text {corr }}$ & $633 \mathrm{MPa}$ & $14,5 \%$ & $32,5 \%$ \\
$\mathbf{3}$ & $-1200 \mathrm{mV} / \mathrm{SCE}, 8 \mathrm{~h}$ & $E_{\text {corr }}$ & $628 \mathrm{MPa}$ & $17,4 \%$ & $38,0 \%$ \\
\hline
\end{tabular}

Figure 11 presents the fracture surface corresponding to the specimen with the bainitic microstructure and tested under condition 1. Figure 11a) presents an overview of the fracture surface. The fracture surface indicates crack initiation at the specimen surface at the bottom of the figure, and crack propagation towards the center of the specimen, followed by final fracture. The reduction of area and almost no necking indicate a macroscopically-brittle fracture of the specimen. The fact that there was necking indicated that the hydrogen induced cracking occurred at or after the ultimate tensile strength. This behavior explains the stress-strain curve from Figure 10b). Detailed observation revealed an abundance of $\mathrm{MnS}$ clusters as indicated in Figure 11b). This micrograph also indicates the presence of some ductility, which confirms the assumption of a curve governed by the centripetal crack propagation. This indicates that the brittle fracture occurred first, inducing a stress drop in this strain-controlled SSRT. This effect was followed by a subsequent failure of ductile ligaments. The brittle areas were mostly transgranular but Figure 11c) shows some intergranular regions located nearby $\mathrm{MnS}$. This fact is emphasized in Figure 11d). 
a)

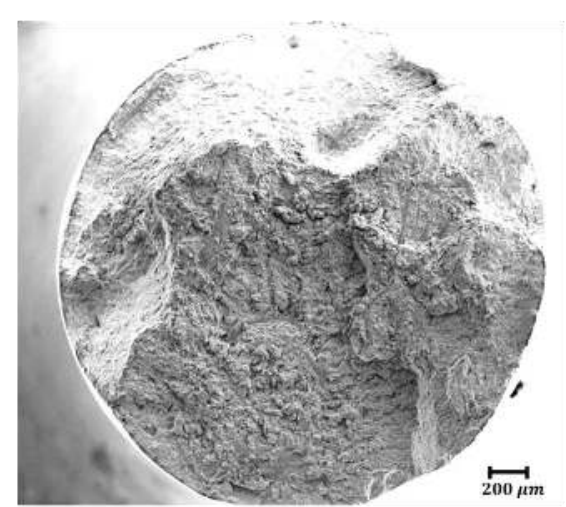

c)

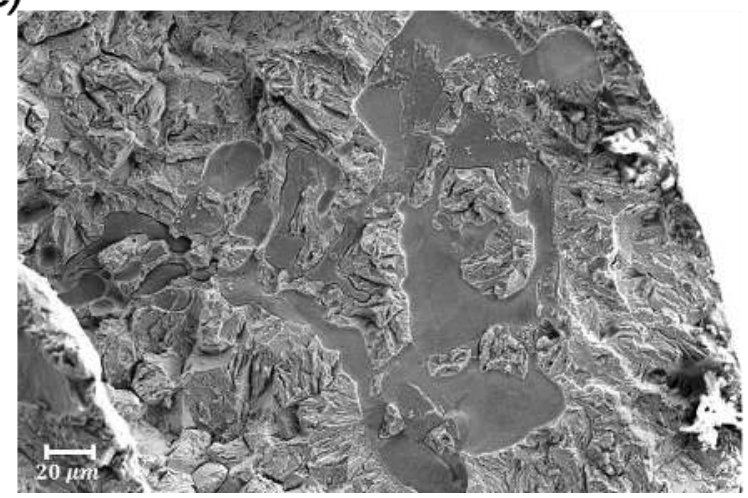

b)

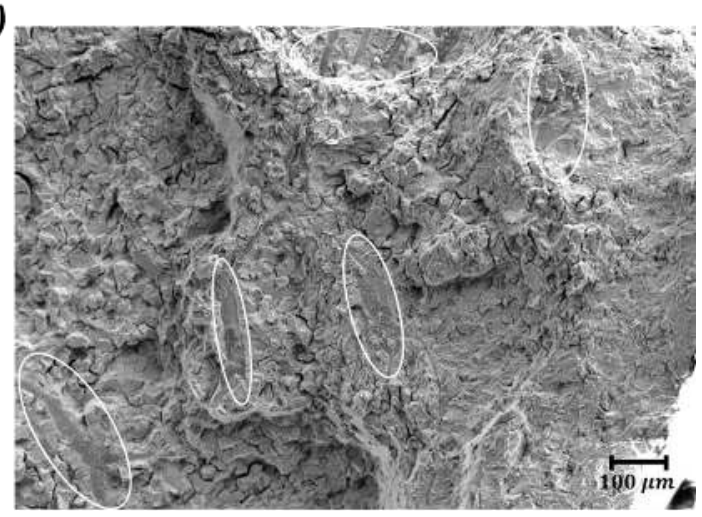

d)

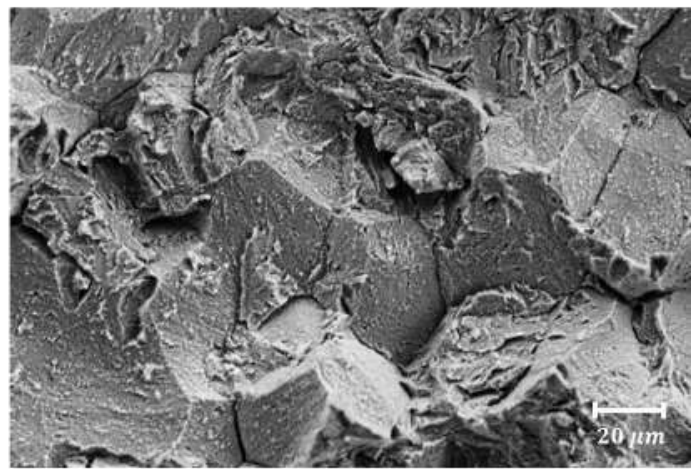

Figure 11 Fracture observation of the bainitic tensile specimen under the first hydrogen loading condition a) global view of the fracture surface, b) presence of elongated MnS inclusions enhancing HE contained in the white elliptic marks c) mixed transgranular-intergranular brittle fracture nearby MnS inclusions (dark smooth surfaces) with some ductile areas, and d) magnification of an intergranular fracture area, located close to $\mathrm{MnS}$ inclusions.

Table 2 and Table 3 present the parameters extracted from the stress-strain curves, respectively for the bainitic and ferrite-pearlite microstructures: the ultimate tensile stress (UTS), elongation to fracture, $\epsilon_{A}$, and cross-section reduction, $\epsilon_{N}$. For the bainitic microstructure, additionally, hydrogen content measurements by catharometry were carried out on $\phi 6 \mathrm{~mm}$ cylindrical specimens for the different charging conditions. The charging conditions 3 and 4 did not produce significant HE, and the hydrogen content was similar to that of the reference specimen. In contrast, there was significant embrittlement resulting from testing conditions 1 and 2. For the bainitic state, there was a decrease of UTS by $13 \%$ in the specimen tested under the condition 1 . The elongation to fracture was decreased by 3.5 times and the section reduced by a factor of 5.4. Under the condition 2, the UTS was reduced by $4 \%$, the elongation to failure by $11 \%$ and the section by $44 \%$. For the ferrite-pearlite microstructure, these quantities were reduced by $(16 \%$, 2.4 times, 2.9 times) and $(4 \%, 15 \%, 38 \%)$ for conditions 1 and 2 respectively.

\subsection{Estimation of fracture toughness from the tensile test}

Figure 11-a) allows a coarse preliminary estimation of fracture toughness for the bainitic microstructure. The stress intensity factor, for a cylindrically-notched cylindrical tensile specimen, is given by (1) and (2) [33]. 
$K_{\mathrm{I}}=\sigma \sqrt{\pi(R-r)} \boldsymbol{f}\left(\frac{r}{R}\right)$

$f\left(\frac{r}{R}\right)=\frac{1}{2} \sqrt{\frac{r}{R}}\left[1+\frac{1}{2} \frac{r}{R}+\frac{3}{8}\left(\frac{r}{R}\right)^{2}-0,363\left(\frac{r}{R}\right)^{3}+0,731\left(\frac{r}{R}\right)^{4}\right]$

where $r$ is the inner radius (at the notch) and $R$ is the outer radius of the specimen. Figure 11a) shows two concentric areas. Assuming that the failure occurred in two steps, the peripheral surface crack can be considered as a pre-crack and the inner section as equivalent to the failure surface in a notched toughness test. The peak load, the average outer radius and the average crack length were measured as $4.58 \mathrm{kN}, 1.33 \mathrm{~mm}$ and $467 \mu \mathrm{m}$ respectively. The resulting fracture toughness under cathodic charging condition was estimated to be $19 \mathrm{MPa} \cdot \mathrm{m}^{1 / 2}$. This coarsely approximated value can be used to determine the expected order of magnitude of the reduced toughness for the dimensioning of the $\mathrm{CT}$ specimen for the measurement of fracture toughness.

\subsection{Estimation of a local fracture toughness in presence of hydrogen}

This experiment targets an evaluation of the local fracture toughness in the presence of hydrogen, in order to quantify the proposed scenario. It is important to underline the word "local" and to recall the complexity of microstructure in such heavy forgings. In fact, the microstructure of the studied materiel is heterogeneous and contains several zones of molybdenum, manganese, carbon and phosphorous over-concentrations in areas named ghost lines and microsegregations. Consequently, typical ASTM standards, like ASTM E399 and E1820 could not be used in order to assess the local value of fracture toughness in the presence of hydrogen, local meaning here : within a millimeter range.

Following our first estimation of $19 \mathrm{MPa} \cdot \mathrm{m}^{1 / 2}$, see above, Irwin's model indicates that the plastic zone radius as given by equation (3) is $104 \mu \mathrm{m}$.

$r_{\mathrm{Y}}=\frac{1}{2 \pi}\left(\frac{K_{\mathrm{IH}}}{\sigma_{\mathrm{Y}}}\right)^{2}$

Table 4 provides the required specimen size, according to the relations presented in ASTM E647 [29]. It is worthy of mentioning that these dimensions satisfy the small-scale yielding (SSY) hypothesis in case of a fracture toughness less than $19 \mathrm{MPa}^{1 / 2}$. For information purposes, the nominal toughness for this steel, typically of the order of $200 \mathrm{MPa} \cdot \mathrm{m}^{1 / 2}$, leads to dimensions of a few dozens of centimeters and extremely high tensile loads. For higher toughness values, a parameter based on the J-integral is more adapted to characterize the elastoplastic material. In the fracture toughness measurement, for repeatability and post processing purposes, the pre-crack was stepwise generated by fatigue as specified in [30] with a sequence of 6 cyclic loading conditions in the $7.96 \mathrm{kN}$ to $2.84 \mathrm{kN}$ range to ensure a progressive decrease of the plastic zone size.

Table 4 -Dimensions of CT specimen for a hydrogen embrittled steel

\begin{tabular}{ccccccccc}
\hline & $\mathbf{H}$ & $\mathbf{B}$ & $\mathbf{w}$ & $\mathbf{a}$ & $\mathbf{w}-\mathbf{a}$ & $\mathbf{w}_{\mathbf{1}}$ & $\mathbf{D}$ & $\mathbf{H}_{\mathbf{1}}$ \\
\hline Dimension $(\mathbf{m m})$ & 15 & 12,5 & 25 & 12,5 & 12,5 & 31,25 & 6,25 & 8,125 \\
\hline
\end{tabular}


The notched CT specimen, of the size given in Table 4, was machined so that crack propagation plane was parallel to the plane of crack formation in the component. Hydrogen was electrochemically charged for $96 \mathrm{~h}$ at $-1200 \mathrm{mV}$ SCE. Thereafter, hydrogen charging was maintained and progressive deformation was applied to this CT specimen up to the final fracture. The displacement of the testing machine was controlled to target a rate of $2 \mathrm{MPa} \cdot \mathrm{m}^{1 / 2} \cdot \mathrm{s}^{-1}$ jointly with continuous load measurement.

Figure 12 presents different aspects of the resulting fracture surface. Figure 12a) presents a global view. At this magnification, a progressive transition from ductile to brittle failure suggests a heterogeneous effect of hydrogen. This progression has been schematized in Figure 12b) which identifies several areas. Near the pre-crack in zone 0 , the failure was mainly ductile with some embrittled areas located near MnS inclusions. The fracture path changed to a brittle mode in zones 2-4. These zones are characterized by the continuous reduction of ductility (e.g. ligaments) with increasing crack length. Figure 12c) presents a micrograph focusing on an embrittled area located in the vicinity of the MnS-inclusion in zone 2. Figure 12d) presents a micrograph focused on a representative area of zone 4 . This zone was fully brittle transgranular with no trace of ductility.

a)

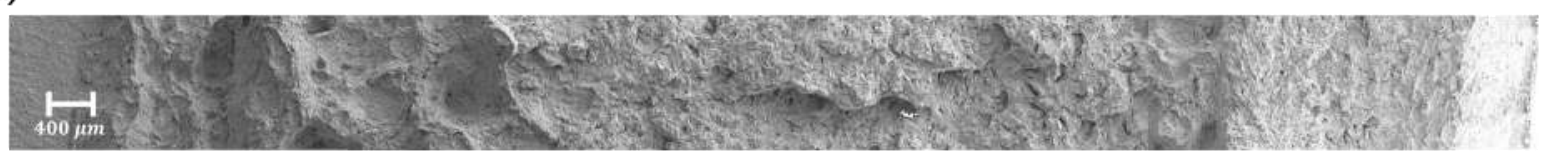

b)

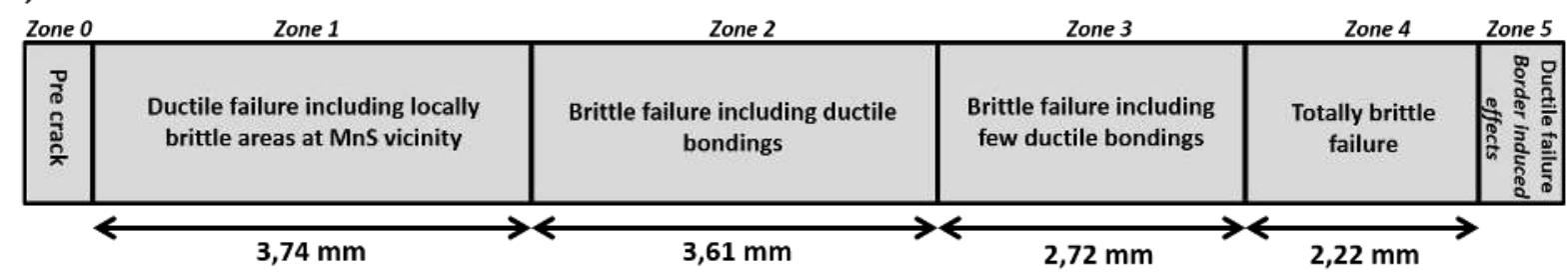

c)

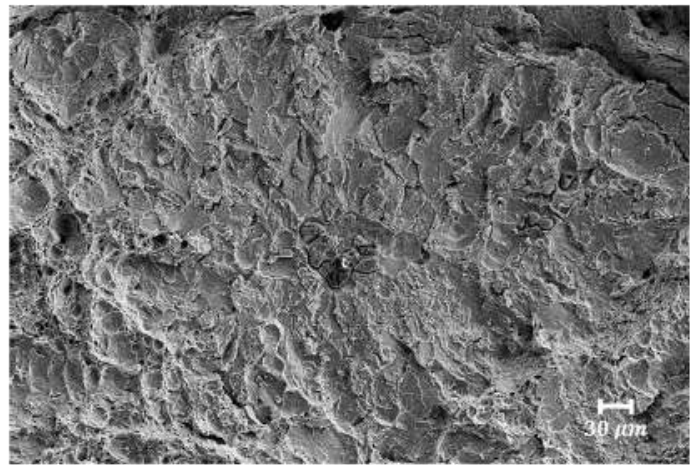

d)

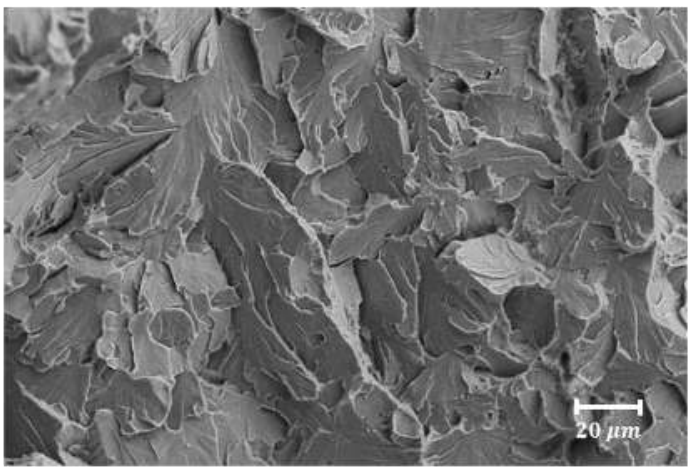

Figure 12 Fracture surface obtained after a fracture toughness test under hydrogen charging conditions at $1200 \mathrm{mV}_{\mathrm{SCE}}$ in $30 \mathrm{~g} \mathrm{~L}^{-1} \mathrm{NaCl}$ for $96 \mathrm{~h}$. a) Overview S EM macrograph of the fracture surface. b) Sche matic of the different areas on this fracture surface. c) Focus on an elliptic brittle area surrounding several MnS inclusions in the zone 2. d) Fully brittle fracture in zone 4. 
Figure 13a) presents the loading curve for this measurement. The overall shape of the curve indicates load increase up to a maximum of $23 \mathrm{kN}$ followed by the progressive load decrease down to approximately $17 \mathrm{kN}$, whereupon there was a steep load drop. The critical event happened during the load increase. Figure 13b) presents a magnification of the ascending part of the loading curve. There was a slight load drop during the test, indicating the damage of the material within the elastic region of the curve. The amplitude of the drop was significantly greater than the acquisition noise. In addition, the load recovery led to a load curve in continuity with the initial slope.

This damage, that had occurred at $4,3 \mathrm{kN}$, was linked to the highly heterogeneous microstructure of this steel, and was attributed to micro-fracture of such a heterogeneous area, situated within the ductile region in zone 1 . In fact, it is worth emphasising that the $18 \mathrm{MnNiMo5}$ steel is a highly heterogeneous bainitic steel containing ghost lines and microsegregated zones, since it is obtained from a very large ingot. While the nominal toughness of this alloy is of the order of 200 $\mathrm{MPa} . \mathrm{m}^{1 / 2}$, individual values well below $100 \mathrm{MPa} \cdot \mathrm{m}^{1 / 2}$ are measured. They reflect intrinsic material heterogeneities, namely microsegregations, which are of submillimeter size, therefore much smaller than the CT fracture surface. Under hydrogen charging, much lower values of fracture toughness are expected due to the hydrogen embrittlement phenomenon.

These results, particularly the load drop at $4,3 \mathrm{kN}$, allow evaluation of fracture toughness based on the CT related expression of stress intensity factor as defined by (4) and (5) [30].

$K_{\mathrm{I}}=\frac{F}{\left(B B_{\mathrm{N}} w\right)^{0,5}} g_{2}\left(\frac{a}{w}\right)$

$g_{2}\left(\frac{a}{w}\right)=\frac{\left(2+\frac{a}{w}\right)\left[0,886+4,64 \frac{a}{w}-13,32\left(\frac{a}{w}\right)^{2}+14,72\left(\frac{a}{w}\right)^{3}-5,6\left(\frac{a}{w}\right)^{4}\right]}{\left(1-\frac{a}{w}\right)^{1,5}}$

where $a$ is the total crack length, $w$ is the maximal crack length to split the CT specimen into two parts, and each of $B$ and $B_{N}$, which were equal in this case, is the specimen thickness.

The fracture toughness corresponding to the peak load of $23 \mathrm{kN}$ was $95 \mathrm{MPa} . \mathrm{m}^{1 / 2}$ but this value was invalid since the plain strain conditions were not satisfied at this load for this specimen. This measurement cannot be interpreted.

The fracture toughness evaluated from the load drop at $4.3 \mathrm{kN}$ was $18 \mathrm{MPa} \cdot \mathrm{m}^{1 / 2}$. This measurement provides an estimation of the reduced local fracture toughness since the plain strain conditions are strictly respected for this load. This value of $18 \mathrm{MPa} \cdot \mathrm{m}^{1 / 2}$ reflects hydrogen effect on the local fracture toughness of a microsegregated area, and has to be considered as an estimate because significant variations can be anticipated depending on the actual position of a microsegregated areas with respect to the crack tip position. 
a)

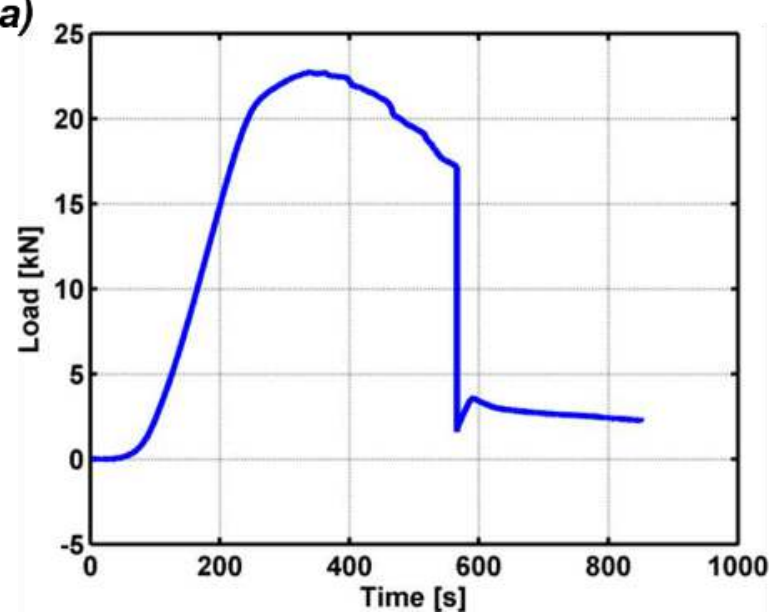

b)

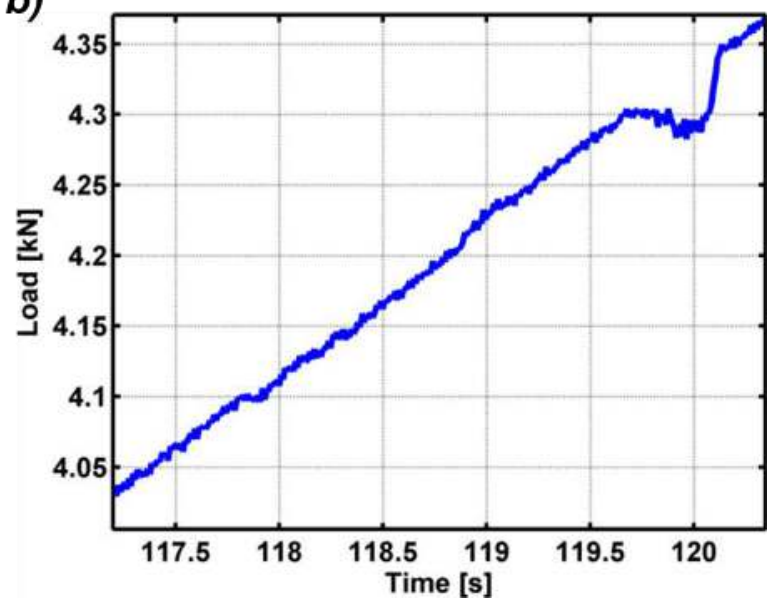

Figure 13 Loading curves for the toughness test using a pre-cracked CT s pecimen under hydrogen charging conditions. a) Overall load-time curve. b) Focus on the load drop at around $4.3 \mathrm{kN}$. This load drop is attributed to the embrittled areas near MnS inclusion in Zone 1 and 2, and can therefore provide a quantitative value for the fracture toughness in the presence of hydrogen of a microsegregated area.

The fracture toughness test showed a heterogeneous effect of hydrogen inducing a progressively brittle fracture mode. The HE heterogeneity can be linked to the hydrogen charging conditions. The hydrogen charging setup used the specimen and both loading jaws as the working electrode. The jaws were protected by a silicone based waterproof coating, which obstructed the front of the specimen and avoided hydrogen charging. Only the back part of the specimen could interact with the counter electrode, so that the specimen was only hydrogen charged from the zones 4-5. The hydrogen charging was performed at a cathodic potential using a deoxygenated saline solution. Such conditions limit the effects of surface and promote adsorption and absorption phenomena. From the viewpoint of a simplified diffusion problem, the concentration of hydrogen decreases linearly from the charging area (zones 4-5) to the crack tip. Since the electrochemical interactions at the crack tip region were limited, the hydrogen concentration at the crack-tip was assumed to be nearly equal to the as-received material (around $0.72 \mathrm{wt}$. ppm, see Table 2) whereas the estimated concentration in zone 5 was close to $1.6 \mathrm{wt}$. ppm, a value based on bulk $\mathrm{H}$ content measurements on independent specimen under the same charging conditions.

Hydrogen trapping models suggest an equilibrium driven process, each trap being defined by an activation energy. The site occupancy rate is closely linked to hydrogen activity. The non-zero value of the hydrogen concentration for the as-received reference specimens was measured by catharometry, and was attributed to a significant amount of hydrogen in deep traps (nondiffusible hydrogen). The hydrogen embrittlement induced by the fracture toughness testing conditions was fairly severe, and was attributed to the lowering of cohesion forces at interfaces by the locally-trapped hydrogen. 


\section{Discussion}

\subsection{Scenario of crack formation}

The starting point of this investigation was the presence of penny-shaped internal cracks, 10-20 $\mathrm{mm}$ in diameter, that were detected by ultrasonic measurements on a 18MND5 component after the final step of the thermo-mechanical manufacturing cycle shown in Fig. 1.

One such crack was extracted and analyzed. The internal crack surfaces were smoothed by temperature activated surface diffusion as demonstrated by the series of UHV heat treatments between $625{ }^{\circ} \mathrm{C}$ and $950{ }^{\circ} \mathrm{C}$. The morpho logy obtained after heating at $950{ }^{\circ} \mathrm{C}$ was comparable to the morphology of the defect extracted from the industrial component, and indicated that the cracks in the component were formed during the slow cooling following the first austenisitation heat treatment, and were then smoothed during the second austenitisation. A detailed morphological analysis indicated that the initial internal surface of the cracks was mainly transgranular with some intergranular areas. Intergranular areas containing MnS clusters were associated with crack initiation, while transgranular areas were associated with crack propagation, as discussed below.

\subsection{Crackinitiation}

It is proposed that crack initiation was provoked by a combination of the following four effects: (i) local pho sphorous segregation facilitating intergranular micro-fracture, (ii) thermal contraction mismatch of the steel and the $\mathrm{MnS}$ inclusion during cooling causing separation of the interface between the steel matrix and the $\mathrm{MnS}$ inclusion, (iii) the distribution of $\mathrm{MnS}$ inclusions in clusters of millimeter size, and (iv) hydrogen desorption at the void at the interface between the steel matrix and the MnS inclusion, and the subsequent hydrogen pressure increase

Firstly, the local phosphorous segregation is compatible with the heterogeneous microstructure of the $200 \mathrm{~mm}$ thick heavy component, where micro-segregations and ghost lines are known to contain an increased amount of phosphorous. The phosphorous is expected to have segregated during the slow cooling, supposed to have been of the order of $10{ }^{\circ} \mathrm{C} / \mathrm{h}$ within the critical range of temperatures between $550{ }^{\circ} \mathrm{C}$ and $350{ }^{\circ} \mathrm{C}$, where thermodynamics and kinetics indicate phosphorous segregation. The resulting phosphorous embrittlement together with increasing internal stresses due to the cooling to room temperature would result in the phosphorous embrittlement of grain boundaries, especially on ghost lines.

Second, the MnS/matrix interface opens during the cooling due to the difference of thermal expansion coefficient, $\beta$, between $12.5 \times 10^{-6} \mathrm{~K}^{-1}$ for $18 \mathrm{MND} 5$ and $16.3 \times 10^{-6} \mathrm{~K}^{-1}$ for $\alpha$-MnS with a $\mathrm{NaCl}$ type lattice. Considering a typical $\mathrm{MnS}$ inclusion with a radius $r_{M n S}$ of $15 \mu \mathrm{m}$, the resulting opening $\delta$ of the metal-MnS interface after a cooling from $620{ }^{\circ} \mathrm{C}$ to $20{ }^{\circ} \mathrm{C}(\Delta T=$ 
$-600{ }^{\circ} \mathrm{C}$ ) is $17 \mathrm{~nm}$, calculated using the expression in equation (6). The MnS/matrix interface is therefore an important factor contributing to the crack initiation.

$\delta=\left(\boldsymbol{\beta}_{\alpha 18 M N D 5}-\boldsymbol{\beta}_{\alpha M n S}\right) \Delta T \boldsymbol{r}_{M n S}$

Third, the fact that these inclusions are in clusters of a millimetric size induces a significant number of such initiation sites and allows the formation of a hydrogen crack of significant initial size.

The proposed scenario is that (i) for $\mathrm{MnS} /$ matrix interfaces located on phosphorous enriched prior austenite grain boundaries, continuous hydrogen desorption to $\mathrm{MnS} / \mathrm{matrix}$ interfaces at room temperatures results in the progressive stress increase at such interfaces, then (ii) these individual decohesions at $\mathrm{MnS} /$ matrix interfaces expand through the region of phosphorous embrittled grain boundaries, and (iii) finally such a crack reaches the external diameter of the ghost lines. The crack initiation is accomplished when such a penny-shaped crack leaves the ghost line and enters the matrix, i.e. the area without $\mathrm{MnS}$ clusters, and without such a high hydrogen content as measured in Table 1, and without the phosphorous segregation. The crack initiation is mainly intergranular, and results in a sub-millimeter penny-shaped cavity with the initial thickness given by the range of thermal mismatch between $\mathrm{MnS}$ and matrix, i.e. of the order of $20 \mathrm{~nm}$. The kinetics of pressure build-up in such a crack, necessary for crack propagation across the matrix, was quantitatively assessed in our two previous papers [3] [4].

In a search of plausible orders of magnitude for the critical fracture toughness, it is instructive to consider the most severe, but still realistic case of such a sub-millimeter initiation site $(a=0.5$ $\mathrm{mm}$ ). For a penny-shaped pressurized crack, the stress intensity factor is given by the expression in equation (7) [31]. The fracture toughness of "healthy" 18MND5 steel is approximately $200 \mathrm{MPa} \cdot \mathrm{m}^{1 / 2}$, so that the resulting critical pressure required to initiate fracture would be as high as $7930 \mathrm{MPa}$.

$K_{I}=\frac{2 p}{\pi} \sqrt{\pi a}$

The fracture toughness of hydrogen embrittled specimen, as estimated in the present paper by two independent methods is below $20 \mathrm{MPa} . \mathrm{m}^{1 / 2}$, so that the resulting critical pressure required to initiate fracture would drop by a factor of ten, down to $793 \mathrm{MPa}$. Our previous assessments indicated a maximum pressure of $860 \mathrm{MPa}$ for a hydrogen concentration of $1 \mathrm{wt}$. ppm [4]. This indicates that the internal hydrogen pressure can cause the penny shaped cracks at the $\mathrm{MnS} /$ matrix interface to grow through the embrittled region. 


\subsection{Crack propagation}

Crack propagation is caused by (i) continuous hydrogen desorption to these cracks and the subsequent hydrogen pressure increase, and (ii) the decrease of fracture toughness due to the presence of hydrogen within the phosphorous enriched material at the crack tip, and (iii) discontinuous crack propagation due to these two elements. The crack initiation is considered to have occurred during the cooling to temperatures slightly above room temperature (which caused the hydrogen pressure build-up). Crack propagation is considered to occur at room temperature where hydrogen solubility is minimal, and as a consequence, the resulting hydrogen pressure can reach the highest value. First, hydrogen desorption results in hydrogen pressure build- up within a period of the order of some hours as demonstrated in our recent paper where hydrogen gas behavior was assessed based on recent NIST data and has led to the equilibrium pressure of 860 MPa [4]. Second, the loss of mechanical properties was expected with the reduction of fracture toughness down to $18 \mathrm{MPa} \cdot \mathrm{m}^{1 / 2}$ under hydrogen charging conditions. This represents a local fracture toughness in the presence of hydrogen, $K_{1 \mathrm{H}}$. Finally, the combination of such a high hydrogen pressure and locally low fracture toughness results in crack propagation, given the millimeter size of the initial crack. A penny-shaped crack, $1 \mathrm{~mm}$ in diameter, together with material fracture toughness of $18 \mathrm{MPa} . \mathrm{m}^{1 / 2}$ leads to a critical pressure of $717.3 \mathrm{MPa}$ according to our previous calculations [4]. As a consequence, the crack propagates in a brittle manner over a distance corresponding to a characteristic microstructural feature, that was arbitrary taken as a size of a bainitic packet. Such a brittle propagation is expected to be fast. It results in a volume increase and pressure decrease which in turn requires more hydrogen to diffuse again to the crack with a new step of a progressive pressure built up, up to a new, slightly lower critical pressure. Such a mechanism implies a discontinuous crack propagation.

In order to gain an order of magnitude of crack propagation rate, a simplified analysis based on the assumption of a constant crack velocity can be performed as follows. In the case of an industrial penny-shaped crack, starting from a millimeter size initiation site, a centimeter size is obtained during approximately one month, which corresponds to an average crack growth rate of $3.7 \times 10^{-9}{\mathrm{~m} . \mathrm{s}^{-1}}$. The differentiation of the stress intensity factor in equation (7) provides an expression for the average experimental velocity in equation (8) that should be targeted (this value being out of range regarding norms).

$\dot{K}_{I}=\frac{p}{\sqrt{\pi a}} \dot{a}$

An internal pressure of $800 \mathrm{MPa}$ leads to a velocity of $9.5 \times 10^{-5} \mathrm{MPa} \cdot \mathrm{m}^{1 / 2} \cdot \mathrm{s}^{-1}$. An increased effect of $\mathrm{HE}$ is then expected in this case of an industrial crack and may lead to an effective value of toughness slightly below $18 \mathrm{MPa} \cdot \mathrm{m}^{1 / 2}$.

A viable path forward to quantify these aspects is a predictive modeling of this industrial problem with a coupled diffusion-mechanical-metallurgical model. The diffusion procedure aims at quantifying the redistribution of hydrogen between the alloy and the hydrogen induced crack. The mechanical procedure targets the kinetic aspects of fracture such as crack length, crack 
growth rate or failure criterion. Finally, the metallurgical model renders various properties of the alloy such as $\alpha \rightarrow \gamma$ transformation and decrease of fracture toughness, induced by hydrogen and phosphorous segregation. This overall scenario of crack propagation can be assessed by a quantitative analysis of crack propagation rate, which is based on above mentioned elements with a strong dependence on fracture toughness, hydrogen solubility and diffusion [32].

\subsection{Possible extension to blister cracking}

Premature and unexpected failure of a component can be promoted by hydrogen in solid solution in alloys, which may have various origins. A distinction is made between internal (i.e. initially present) [34] [35] and external hydrogen, which requires a contribution from the environment, mainly from electrochemical reactions occurring in operation [36] [37] [38] [39] .

The overall scenario of embrittlement, together with underlying mechanisms, i.e. (i) segregation of embrittling elements, (ii) hydrogen desorption first to the interfaces with inclusions, and then to the as-initiated crack, and (iii) transgranular crack propagation under the action of hydrogen pressure within the material, itself embrittled by the presence of hydrogen and phosphorous, can be applied to several similar situations, where hydrogen initially comes from external charging, but eventually acts as internal hydrogen in a similar manner to that described in the present paper.

Hydrogen induced cracks (usually shorten to HIC, also known as "blisters" in the Oil and Gas industry [10]) are a typical example of such cracks, and could be analyzed according to the same scenario of propagation, the only difference being the origin of hydrogen. The subsequent mechanism might be similar to mechanism proposed by [22] where HIC forms in the presence of $\mathrm{H}_{2} \mathrm{~S}$ (external hydrogen source) in sour environment conditions, where the hydrogen fugacity and consequently pressure is known to be high.

Similar cracks would be expected for corrosion in acidified environments, for example in the solutions associated with pits and crevices, as significant hydrogen fugacities have been shown to occur for steels in acid solutions [40].

Despite these similarities, additional factors, not directly considered in the present study, could have an impact on cracks caused by hydrogen as raised in [41], [42], [43]. In these references, several parameters such as stress resulting from thermal expansion, phase transformation, metallurgical parameters (e.g. grain size, impurities), segregation were investigated bringing some nuance to the analogy between the blisters and the HIC observed in large components. 


\subsection{Hydrogen induced localised damage (HILD)}

The approach developed herein can be generalized to other cases of hydrogen induced cracking. The general concept is that there is brittle crack extension for a limited distance in front of a crack tip, if the crack tip stress intensity factor at the crack tip is greater than the locallyembrittled fracture toughness ahead of the crack tip. This process can repeat if the new crack tip region can subsequently become embrittled. This mechanism of hydrogen induced cracking (HIC) can be designated as Hydrogen Induced Localised Damage (HILD). The present work has dealt with embrittlement by hydrogen. The approach is in principle valid, independent of the species causing embrittlement. In this case the mechanism can be designated as Environment Induced Localised Damage (EILD). Furthermore, procedures have been developed herein by which the locally embrittled fracture toughness can be measured.

There are two possible rate-limiting factors on the average crack velocity. One is the distance of brittle crack extension. The brittle crack might extend only through the embrittled region and may be stopped when the crack reaches un-embrittled material. Although the whole steel is hydrogen embrittled, the level of embrittlement is not uniform. In addition, the fast brittle crack propagation is prevented by the slow desorption of hydrogen to put the crack void under high pressure.

It is also worth pointing out, that this mechanism does NOT directly involve any of the current models of hydrogen embrittlement, such as hydrogen enhanced localized plasticity (HELP), hydrogen enhanced decohesion (HEDE) or adsorption induced dislocation emission (AIDE). Instead, the critical event is the brittle fracture through a local region ahead of the crack tip, the region having been embrittled.

\subsection{Lessons for industrial production}

It is worth underlining that the cracks analyzed in this paper formed as a consequence of the combination of (i) a high hydrogen content close to the upper limit of $1 \mathrm{ppm}$ and (ii) the unplanned slow furnace cooling and subsequent long period of storage at room temperature before the second austenitisation. High phosphorous concentrations at former austenite grain boundaries and the presence of large $\mathrm{MnS}$ clusters, both mainly within ghost lines, allowed crack initiation by a hydrogen mechanism. Room temperature hydrogen desorption is considered as a main cause of subsequent crack propagation and eventually penny-shaped cracks formation up to $20 \mathrm{~mm}$ diameter.

It is however important to underline that the appropriate process control measures allow for the complete elimination of such defects from large forged components. 


\subsection{Conclusions}

This study analyzed a crack from the scrapped 18MND5 80-tonne component in order (i) to identify the critical step in crack formation, (ii) to propose a crack initiation and propagation scenario, and (iii) to understand the underlying physical mechanisms. The conclusions are as follows:

1. The smoothed morphology of the internal surface of the crack withdrawn from a 18MND5 shell, together with a series of purpose designed ultra-high vacuum heat treatments on mixed intergranular/transgranular fracture surfaces, indicated that the crack was formed during the unexpected slow cooling in furnace after the first autenitisation heat treatment.

2. The subsequent second austenitisation transformed the brittle fracture surface into a smooth surface strongly affected by surface diffusion.

3. The root cause of crack formation was the low fracture toughness caused by a combination of a high hydrogen content and phosphorous segregation in micro-segregated areas, where phosphorous segregation can be twice as high as in the matrix.

4. Cracks initiated on $\mathrm{MnS}$ inclusion clusters of millimeter size, that were located within ghost lines, where there was phosphorous segregation to prior austenite grain boundaries during exceptionally slow cooling. Hydrogen desorption at $\mathrm{MnS} /$ matrix interfaces would result in penny-shaped, approximately $1 \mathrm{~mm}$ in diameter and thin cracks.

5. Mechanical tests under hydrogen charging conditions demonstrate a significant decrease in fracture toughness, here down to $18 \mathrm{MPa} . \mathrm{m}^{1 / 2}$. This absolute value reflects a local hydrogen effect on a microsegregated area and has to be considered as an order of magnitude because significant variations can be anticipated depending on the actual position of a microsegregated areas with respect to the crack tip position.

6. The fracture toughness value of the order of $18 \mathrm{MPa} . \mathrm{m}^{1 / 2}$ together with previously calculated hydrogen pressure, of the order of $860 \mathrm{MPa}$, due to hydrogen desorption and presence of penny-shaped $1 \mathrm{~mm}$ diameter cracks, constitute the condition for transgranular crack propagation to a final dimension of the order of $10 \mathrm{~mm}$ in diameter.

7. The cracks in the component were caused by the inappropriate heat treatment (in particular the slow cooling to room temperature) and the presence of an unusually high hydrogen content at temperatures below $200^{\circ} \mathrm{C}$.

8. The proposed hydrogen induced cracking (HIC) mechanism can be designated as Hydrogen Induced Localised Damage (HILD) or more generally Environment Induced Localised Damage (EILD).

9. The appropriate process control measures allow for the complete elimination of such defects from large forged components.

\section{Declaration of Competing Interest}

None. 


\subsection{Acknowledgements}

This work was done at Mines Saint Etienne (MSE, France) in the frame of Jean-Gabriel SEZGIN's PhD degree between 2014 and 2017. The author acknowledges the colleagues from Mines Saint Etienne, Areva (now: Framatome), the University of Queensland (Australia) and National Institute of Advanced Industrial Science and Technology (AIST, Japan) for their continuous support and kind collaboration on this publication.

\section{References}

[1]

C.Naudin et al.,'Intergranular fracture stress and phosphorus grain boundary segregation of a Mn-Ni-Mo steel", Scripta Materialia, vol.40 nº, 1999, pp. 1013-1019

L.Bedel et al.,"Comparaison des aciers de cuve utilisés dans les Rupther et Krakatoa", Technical Note DEM $\mathrm{n}^{\circ} 98 / 15$, CEA Grenoble

J.G.Sezgin et.al., "Modelling of hydrogen redistribution in a heterogeneous alloy and simulation of cooling down to $200^{\circ} \mathrm{C}$ ", Int. J. of Hy drogen Energy (2017), http://dx.doi.org/10.1016/j.ijhy dene.2017.03.095

J.G.Sezgin et.al.," Modelling of hy drogen induced pressurization of internal cavities ", International Journal of Hydrogen Energy, Vol. 42 (2017), pp. 15403-15414

L. Coudreuse, «Fragilisation par l'hydrogène et corrosion sous contrainte; Corrosion sous contrainte phénoménologie et mécanismes », Ed. D. Desjardins et R. Oltra, Les Editions de Physique, 1992, pp. 397-424

J. Venezuela et al., "A review of hydrogen embrittlement of martensitic advanced high strength steels", Corrosion Reviews, 34 (2016) pp. 153-186

Q. Liu et al., "A review of the influence of hydrogen on the mechanical properties of DP, TRIP and TWIP advanced high strength steels for auto construction", Corrosion Reviews, 34 (2016), pp. 127-152.

Q Liu et al., "A critical review of the influence of hydrogen on the mechanical properties of medium strength steels", Corrosion Reviews, 31 (2013), pp. 85-104

S Ramamurthy et al., "Stress Corrosion Cracking of High Strength Steels", Corrosion Reviews, 31 (2013), pp. 131

D.P.Dunne et al., "Investigation of the effect of electrolytic hydrogen charging of X70 steel : I. The effect of microstructure on hydrogen-induced cold cracking and blistering", Int. J. Hydrogen Energy, vol. 41, 2016, pp.

$12411-12423$

R. Kirchheim, "Reducing grain boundary, dislocation line and vacancy formation ener gies by solute segregation. I. Theoretical background", Acta Materialia, vol.55 (15), 2007, pp. 5129-5138

R. Kirchheim, "Reducing grain boundary, dislocation line and vacancy formation energies by solute segregation.

II. Experimental evidence and consequences", Acta Materialia, vol.55 (15), 2007, pp. 5139-5148

R. Kirchheim, "Revisiting hydrogen embrittlement models and hydrogen-induced homogeneous nucleation of dislocations", Scripta Materialia, vol.62(2), 2010, pp.67-70

J. Venezuela et al., "The influence of hydrogen on the mechanical and fracture properties of some advanced high strength steels studied using the linearly increasing stress test", Corrosion Science, 99 (2015), pp. 98-117.

Q Liu et al., "The influence of hydrogen on $3.5 \mathrm{NiCrMoV}$ steel studied using the linearly increasing stress test", Corrosion Science, 67 (2013), pp. 193-203.

Q Liu et al., "Influence of hydrogen on the mechanical properties of some medium strength Ni-Cr-Mo steels", Materials Science and Engineering A, 617 (2014), pp. 200-210

A.R. Troiano, "The role of hydrogen and other interstitials in the mechanical behavior of metals", Trans. ASM, vol. 52,1960, p. 54

N.J Petch et. al., "Delay ed Fracture of Metals under Static Load", Nature, vol. 169, 1952, pp. 842-843

S. Matsuoka et. al., "Effect of hydrogen and prestrain on tensile properties of carbon steel SGP $(0.078 \mathrm{C}-0.012 \mathrm{Si}$ $-0.35 \mathrm{Mn}$, mass \%) for $0.1 \mathrm{MPa}$ hydrogen pipelines”, Trans JSME A, vol. 74 (744), 2008, pp. 1164-1173

T. Matsuo et. al., "Fatigue crack growth properties of quenched and tempered Cr-Mo steel in $0.7 \mathrm{MPa}$ hy drogen gas", ECF 18 conference proceedings, 2010 
[21] N.J Petch, “The lowering of fracture-stress due to surface adsorption”, Philosophical Magazine, vol. 1(4), 1956, pp. 331-337

C.A. Zapffe et. al., "Hydrogen embrittlement, internal stress and defects in steel." Trans. AIME 145, 1941, pp 225-271. -

[23] Masoumi, M., Silva, C. C., \& de Abreu, H. F. G. (2016). Effect of crystallographic orientations on the hydrogeninduced cracking resistance improvement of API 5L X70 pipeline steel under various thermomechanical processing. Corrosion Science, 111, 121-131, DOI: 10.1016/j.corsci.2016.05.003 Mohtadi-Bonab, M. A., Karimdadashi, R., Eskandari, M., \& Szpunar, J. A. (2016). Hydrogen-induced cracking assessment in pipeline steels through permeation and crystallographic texture measurements. Journal of Materials Engineering and Performance, 25(5), 1781-1793. DOI : 10.1007/s11665-016-2021-8

Du, X. S., Cao, W. B., Wang, C. D., Li, S. J., Zhao, J. Y., \& Sun, Y. F. (2015). Effect of microstructures and inclusions on hydrogen-induced cracking and blistering of A537 steel. Materials Science and Engineering: A, 642, 181-186.Volume 642, 26 August 2015, Pages 181-186, DOI: 10.1016/j.msea.2015.06.085

Mohtadi-Bonab, M. A., \& Eskandari, M. (2017). A focus on different factors affecting hydrogen induced cracking in oil and natural gas pipeline steel. Engineering Failure Analysis, 79, 351-360.

https://doi.org/10.1016/j.engfailana1.2017.05.022

J.Campbell,"Complete Casting Handbook : Metal Casting Processes, Techniques and Design", Elsevier Science, 2011, pp.246-253

ASTM E647 - 15e1 Standard Test Method for Measurement of Fatigue Crack Growth Rates, 2001 pp. 627-669

D. Francois, "Essais de mesure de la ténacité - Mécanique de la rupture", Techniques de l'ingénieur, m4166, 2007

Y. Murakami, "Stress Intensity Factors Handbook”, vol.1 \& 2, Pergamon Press, 1987

J.G.Sezgin et.al., "A model of internal crack extension due to a continuous build-up of hy drogen pressure: application to a pressure vessel component", to be submitted to Acta Materialia. pp.105-123

R.L.S.Thomas et. al, 'Internal hydrogen embrittlement of ultra-strength AERMET 100 steel”, Metallurgical and Materials Transaction A, vol.34 Issue 2, 2003, pp.327-344

R.D. Kane et al.,"Roles of $\mathrm{H}_{2} \mathrm{~S}$ in the behavior of engineering alloys: a review of literature and experience", Corrosion/98, paper n ${ }^{\circ} 274$, NACE International, 1998

Y.Chen et al.,'Influence of $\mathrm{H}_{2} \mathrm{~S}$ interaction with prestrain on the mechanical properties of high-strength X80 steel”, Int. J. of Hy drogen Energy, vol. 41, 2016, pp.10412-10420

P.Wang et al.,"Effect of $\mathrm{H}_{2} \mathrm{~S} / \mathrm{CO}_{2}$ partial pressure ratio on the tensile properties of X80 pipeline steel", Int. J. of Hydrogen Energy, vol. 40, 2015, pp.11925-11930

F. Ruel et al., "The Influence of Temperature and pH on the EAC Behavior of the UNS(1) S32304 Lean Duplex Stainless Steel”, Corrosion/14 Conference paper, NACE International, 2014

Darken L.S., Smith R.P. "Behavior of hydrogen in steel during and after immersion in acid", Corrosion, 1949, 5.1: $1-16$.

Brainin, I. E. "Shatter cracks and the effect of heat treatment conditions on the elimination of hydrogen from steel", Metal Science and Heat Treatment, 1971, 13.1: 46-48.

Scott T. E., Troiano, A. R. "Hydrogen and segregates in flaking", JOM, 1959, 11.9: 619-622.

[43] Houdremont E., Korschan H., "Die Entstehungsbedingungen der Flocken im Stahl”, Stahl und Eisen, 1935 , vol. 55, pp. 297-304.

\section{Highlights}

- An experimental analysis of industrial HIC in heavy components was conducted

- SEM imagery shows a smoothed mixt intergranular and transgranular failure surface

- In situ SSRT \& toughness tests revealed a strong Hydrogen Embrittlement of steel

- MnS located near ghostlines (enriched in P) act as millimetric initiation sites

- A HIC mechanism accounting for HE, $\mathrm{P}$ segregation and $\mathrm{H}$ precipitation was proposed 